\title{
Design of a new generation of sustainable SBR compounds with good trade-off between mechanical properties and self-healing ability
}

Marianella Hernández Santana*, María Huete, Patricia Lameda, Javier Araujo, Raquel Verdejo and Miguel A. López-Manchado

Institute of Polymer Science and Technology (ICTP-CSIC), Juan de la Cierva 3, Madrid 28006, Spain

*corresponding author: marherna@ictp.csic.es

\begin{abstract}
Self-healing polymers typically face an enforced trade-off between repairability and mechanical properties, with a high degree of self-healing being achieved mainly by materials having low mechanical strength and stiffness. This study focuses on the development of SBR compounds that can combine together self-healing properties with the use of ground tire rubber (GTR) as alternative sustainable filler. The self-healing efficiency of GTR filled SBR compounds is compared to conventional carbon black filled compounds. The influence of the vulcanization system and the addition of silane-based coupling agents are also assessed. Results show that SBR compounds vulcanized by means of a semi-efficient sulfur based system recover around $50 \%$ of their mechanical strength, being the self-healing response related to the presence of disulfide bonds. Contrary to carbon black compounds, GTR samples present similar healing efficiency to the unfilled SBR samples, improving mechanical properties in 50\%. Moreover, the coupling agent enhances even more (up to 80\%) the mechanical strength of the SBR-GTR compounds without adversely affecting the healing efficiency. These results can thus be seen as a starting model material for developing new sustainable applications economically and environmentally convenient with good mechanical properties as well as healing ability.
\end{abstract}

KEYWORDS: styrene-butadiene rubber (SBR), self-healing, ground tire rubber (GTR), mechanical properties, silane, sustainable

\section{INTRODUCTION}

Elastomers are a special class of polymeric materials with a wide range of application. Apart from their common use in our daily life as tires or shoes they are also extensively used in other industrial sectors like the aerospace or the biomedical industry. Such a widespread usage is due to the unique properties these materials display, namely their large elastic deformation and their excellent noise and vibration damping capabilities. While these materials can sustain large deflections with little or no permanent deformation, elastomers can also fail through fracture and fatigue processes. This inherent weakness makes the prospect of self-healing materials more than ever attractive. Intrinsic self-healing polymers make use of reversible moieties to obtain on-demand or autonomous repair of macroscopic, microscopic or even molecular damages leading to the loss of certain functionality.[1]

Developments of self-healing rubbers started with the pioneering work of Cordier et al. in 2008.[2] They reported the synthesis of an autonomous healing rubber based on supramolecular assembly. Since then, many different healing routes have been developed and new families of 
self-healing rubbery-like materials and crosslinked elastomers have evolved.[3-19] All selfhealing methods have the aim to generate crosslinks in networks, either by physical interactions (molecular interdiffusion/rearrangements), and/or by chemical reactions of various kinds of functional groups (dynamic bonds). In general terms, the first steps of healing involve physical interactions, while at later stages, the chemical reactions occur. Over time the rearrangement of the chains on the damaged surface progresses into diffusion on a low level, and then further into a seemingly random and complete diffusion of the chains, making the material appear as one again.[20] As an example, Yamaguchi et al. designed polyurethanes (PU) in which the chemically controlled chain ends facilitated the autonomous healing of a fully cut polymer at $\mathrm{T}>\mathrm{T}_{\mathrm{g}}$ in about 10min.[3] It was hypothesized that the relatively long distance between the free end of the molecule and its first physical crosslink point ("the dangling length") facilitate the observed crack disappearance. In a later review paper, the healing efficiency of similar PU was presented and defined as the tear strength of the healed material over the virgin material.[18] The phenomenon of healing facilitated by dangling chains has also been investigated leading to high healing degrees at room temperature in a mechanically interesting thermoplastic elastomer.[15] In their work the authors used a biobased aliphatic dimer diamine (DD1). The synthesis of DD1 with a dianhydride (DA) led to a densely branched polyetherimide where 9-C aliphatic chains act as the dangling brushes. By varying the ratio of the DD1/DA and using multiple techniques the authors unveiled the healing mechanism and showed the multiple healing steps leading to a full interfacial recovery.

Despite all the research taking place and positive proof-of-concept, results are still far from satisfactory when thinking about extrapolating them to real life applications. Healing requires chain mobility and, therefore, seems to be in direct contradiction with the fixation needed to form a permanent network in a fully crosslinked elastomer. Therefore, the challenge of obtaining a crosslinked network with weaker covalent bonds that can infer healing capabilities to the rubber as well as good mechanical properties still remains. The inclusion of fillers can then be considered as a good approach for improving the overall mechanical performance of self-healing rubbers.

Nanofillers of different nature have been added to various self-healing rubbers. Li et al.[21] prepared a covalently bonded graphene oxide/polyurethane (GO/PU) composite with significant reinforcement and thermally healable properties. The use of attapulgite (AT) as nanofiller in PU systems has also caught attention and can be seen as a promising low cost replacement for carbon nanotubes (CNTs) and graphene which are far more costly. A series of PU/AT nanocomposites were prepared by solution blending by $\mathrm{Xu}$ and Chen.[22] They added 1 to 5\% of AT to a self-healing PU based on disulfide bonds and shape memory effect. After a healing process of $4 \mathrm{~h}$ at $80^{\circ} \mathrm{C}$, all samples regained different levels of their original tensile strength. Another example of enhancement of mechanical properties without detriment of healing capability was reported by Kuang et al.[23] adding MWCNTs to SBR on the basis of DielsAlder bonding. The nanotubes played dual roles of reinforcing and healing agent. Nanofillers can also be used for restoring other functionalities, i.e. non-mechanical properties such as thermal conduction, electrical conduction and magnetic shielding, among others. Hernández et al.[24] aimed at restoring more than one functionality after healing a macroscopic damage in NR/graphene composites. They evaluated the restoration of electrical and thermal conductivity in a mechanically damaged sample. They found that the dependence of the various healing efficiencies with graphene content is due to a combination of the graphene induced lower crosslinking density, as well as the presence of strong polymer-graphene interactions at the healed 
interphase. Fu et al.[25] developed a new kind of thermally reversible self-healing PU that simultaneously had good processing properties, high thermal stability and improved electrostatic dissipation capacity. With small loadings of CNTs (1-2wt.\%), they achieved a healing efficiency as high as $93 \%$.

Ground tire rubber (GTR) and reclaimed rubber are also used in the rubber industry as cheap substitutes for fillers and elastomers in rubber compounds and even in asphalt mixtures for road construction or in cement-based materials, amongst others. Several reviews have recently been published giving a thorough assessment on processing GTR into polymeric systems.[26-28] The size reduction method in the form of grinding is among the most commonly applied end-of-life recycling technique for waste tires. It appears to be more "green" than the devulcanization process, relying on mechanical shear stress to break the crosslinking bonds, although some researchers have recently proposed alternative green devulcanization processes for the recycling of rubber vulcanizates.[29-30] Mechanical disintegration of the waste tire rubber is conducted at room temperature or under cryogenic conditions until the required particle size is reached. Grinding conditions are of great practical relevance because the properties of compounds are mostly controlled by particle size distribution and mean particle size and thus, by interphase interactions between matrix and waste rubber.

This work is part of an ongoing study that aims to develop elastomeric systems that can combine together self-healing properties with the use of waste rubber. With no doubt, this research appears as an innovative route and key challenge for developing new sustainable applications economically, energetically and environmentally convenient. Thus, the purpose of the present work is to develop eco-friendly self-healing SBR compounds. Hence, the use of ground tire rubber (GTR) as alternative filler will be assessed and compared to traditional fillers, like carbon black. The presence of coupling agents will be considered as well.

\section{EXPERIMENTAL}

\section{Materials and compounding}

Styrene-butadiene rubber (E-SBR Europrene 1502), commercial grade vulcanizing additives and carbon black filler (N-330) supplied by Cabot were used as-received. Ground tire rubber (GTR) obtained by ambient grinding of used tires (combination of passenger car and truck tires of unknown composition) was supplied by Signus. A coupling agent bis[3(trietoxysilyl)propyl]tetrasulfide (Sigma Aldrich) from hereon called TESPT was also incorporated in selected recipes. Rubber compounds were prepared according to the compositions shown in Table 1 and Table 2, varying the accelerant/sulfur ratio (A/S), the filler content and type (N-330 and GTR) and the coupling agent content. The amount of sulfur was kept constant in all compositions.

Table 1. SBR compound recipes in phr (parts per hundred parts of rubber), varying A/S ratio and carbon black $(\mathrm{CB})$ content.

\begin{tabular}{ccccccc}
\hline \multirow{2}{*}{$\begin{array}{c}\text { Ingredients } \\
(\text { phr })\end{array}$} & $\mathbf{C 1}$ & $\mathbf{C 2}$ & $\mathbf{C 3}$ & $\mathbf{C 2 - 1 0 C B}$ & $\mathbf{C 2 - 2 0 C B}$ & $\mathbf{C 2 - 3 0 C B}$ \\
& $\mathrm{A} / \mathrm{S}=0.2$ & $\mathrm{~A} / \mathrm{S}=1$ & $\mathrm{~A} / \mathrm{S}=4$ & $\mathrm{~A} / \mathrm{S}=1$ & $\mathrm{~A} / \mathrm{S}=1$ & $\mathrm{~A} / \mathrm{S}=1$ \\
\hline $\mathrm{SBR}$ & 100 & 100 & 100 & 100 & 100 & 100 \\
$\mathrm{ZnO}$ & 5 & 5 & 5 & 5 & 5 & 5
\end{tabular}




\begin{tabular}{ccccccc} 
SA & 1 & 1 & 1 & 1 & 1 & 1 \\
CBS & 0.14 & 0.70 & 2.80 & 0.70 & 0.70 & 0.70 \\
S & 0.70 & 0.70 & 0.70 & 0.70 & 0.70 & 0.70 \\
N-330 & 0 & 0 & 0 & 10 & 20 & 30 \\
\hline
\end{tabular}

Table 2. SBR compound recipes in phr (parts per hundred parts of rubber), varying TESPT content and with GTR as filler.

\begin{tabular}{cccccc}
\hline \multirow{2}{*}{$\begin{array}{c}\text { Ingredients } \\
\text { (phr) }\end{array}$} & \multicolumn{5}{c}{ Compound } \\
\cline { 2 - 6 } & $\mathbf{C 2 - 2 . 5}$ & $\mathbf{C 2 - 5}$ & $\mathbf{C 2 - 1 0}$ & $\mathbf{C 2 - G T R 1}$ & $\mathbf{C 2 - 5 - G T R 1}$ \\
& $\mathrm{A} / \mathrm{S}=1$ & $\mathrm{~A} / \mathrm{S}=1$ & $\mathrm{~A} / \mathrm{S}=1$ & $\mathrm{~A} / \mathrm{S}=1$ \\
\hline $\mathrm{SBR}$ & 100 & 100 & 100 & 100 & 100 \\
ZnO & 5 & 5 & 5 & 5 & 5 \\
$\mathrm{SA}$ & 1 & 1 & 1 & 1 & 1 \\
$\mathrm{CBS}$ & 0.70 & 0.70 & 2.80 & 0.70 & 0.70 \\
$\mathrm{~S}$ & 0.70 & 0.70 & 0.70 & 0.70 & 0.70 \\
TESPT & 2.5 & 5 & 10 & & 5 \\
GTR1 & 0 & 0 & 0 & 10 & 10 \\
\hline
\end{tabular}

Mixing was performed in an open two-roll mill (Comerio Ercole MGN-300S) at room temperature. The rotors operated at a speed ratio of 1:1.2. First, rubber was passed through the rolls until a band was formed. The activating complex (zinc oxide ( $\mathrm{ZnO}$ ), stearic acid (SA)), TESPT and filler (N-330 or GTR) were then progressively added to the rubber and, finally, the curatives (N-cyclohexylbenzothiazole-2-sulphenamide (CBS) and sulfur (S)) were added.

The crosslinking process was followed using a Rubber Process Analyzer (Alpha Technologies RPA2000) at curing temperature $\mathrm{T}_{\mathrm{c}}=160^{\circ} \mathrm{C}$, frequency $0.833 \mathrm{~Hz}$ and $2.79 \%$ strain for $60 \mathrm{~min}$, monitoring the torque variation as function of time. The compounds were then vulcanized in an electrically heated hydraulic press (Gumix) at $160^{\circ} \mathrm{C}$ and $200 \mathrm{MPa}$ according to their $\mathrm{t}_{90}$ as derived from the corresponding curing curves. Samples were cut out from press-cured sheets to perform damage and healing tests. As-produced samples were optically homogeneous and free of bubbles or other defects.

\section{Material characterization}

Crosslinking density. The average mass of network chains between crosslinks (crosslinking density, v) was determined on the basis of solvent-swelling measurements in toluene by application of the Flory-Rehner[31] equation and assuming the formation of tetra-functional crosslinks during the vulcanization reaction.

Differential scanning calorimetry (DSC). Differential scanning calorimetry (Mettler Toledo DSC $822^{\mathrm{e}} / 500$ ) was performed at a scan rate of $10^{\circ} \mathrm{C} / \mathrm{min}$ in the temperature range from -90 to $25^{\circ} \mathrm{C}$, following a heating/cooling/heating cycle in nitrogen atmosphere. The mid-point of the transition was taken as the value of $\mathrm{T}_{\mathrm{g}}$. The accuracy of the determination was $\pm 1^{\circ} \mathrm{C}$ in each case.

Thermogravimetric analysis (TGA). Thermogravimetric curves were obtained using a thermal analyzer (Mettler-Toledo TA851 ${ }^{\mathrm{e}}$ ). Samples of $\sim 5 \mathrm{mg}$ were heated from 25 to $630^{\circ} \mathrm{C}$ under 
nitrogen atmosphere and in air from 630 to $1000^{\circ} \mathrm{C}$ at a heating rate of $30^{\circ} \mathrm{C} / \mathrm{min}$. Degradation temperature was taken as the inflection point.

Fourier transform infrared spectroscopy (FT-IR). FT-IR spectra (Perkin Elmer Spectrum one) of GTR and rubber compounds were recorded in ATR mode, in a wavenumber range from 4000 to $400 \mathrm{~cm}^{-1}$. Data were collected at $4 \mathrm{~cm}^{-1}$ resolution co-adding 4 scans per spectrum.

Scanning electron microscopy (SEM). Morphological analysis of SBR compounds and GTR was achieved by scanning electron microscopy performed in a SEM (Philips ESEM XL30) equipped with a tungsten filament. Samples were sputter-coated with gold-palladium prior to observation.

Grinding. Selected GTR was further pulverized under cryogenic conditions using a Cryomill (Retsch). A milling protocol consisting of 18 cycles ( $2 \mathrm{~min}$ grinding, $1 \mathrm{~min}$ intermediate cooling) was tested. Other milling protocols are being discussed in an upcoming paper.

Particle size distribution. GTR powder $(\sim 0.05 \mathrm{~g})$ was previously dispersed in $20 \mathrm{ml}$ of a water/ethanol 70/30 solution with $0.2 \mathrm{ml}$ of surfactant Triton X-100. The suspension was sonicated for about $2 \mathrm{~h}$. The particle size distribution was obtained by means of a laser scattering particle size distribution analyzer (Coulter LS 200). A volume standard cumulative distribution was measured under stabilized conditions. Each sample was subjected to a 60 s optical measurement.

Density. The density of GTR samples was determined by hydrostatic weighing method in accordance with the standard ISO 2781.

Tensile testing. Dog-bone shape samples were used for uniaxial tensile testing. Tests were done on a universal mechanical testing machine (Instron 3366) equipped with a $1 \mathrm{kN}$ load cell. Samples were stretched until failure at a constant crosshead speed of $500 \mathrm{~mm} / \mathrm{min}$ at room temperature. Stress at break (ultimate stress) and strain at break (ultimate strain) were determined in order to mechanically characterize the SBR compounds and to evaluate their healing efficiency.[32] Data reported represent the average value from at least five samples.

Mechanical healing. In order to mechanically quantify the healing efficiency, the two separated parts of the tensile tested samples were carefully repositioned together by hand and allowed to equilibrate at room temperature for $24 \mathrm{~h}$. Afterwards, they were healed in a hydraulic press at $70^{\circ} \mathrm{C}$ and 10bar for $7 \mathrm{~h} .[11,33-35]$ Healed samples were retested according to the same tensile test conditions, as represented in Figure 1. 


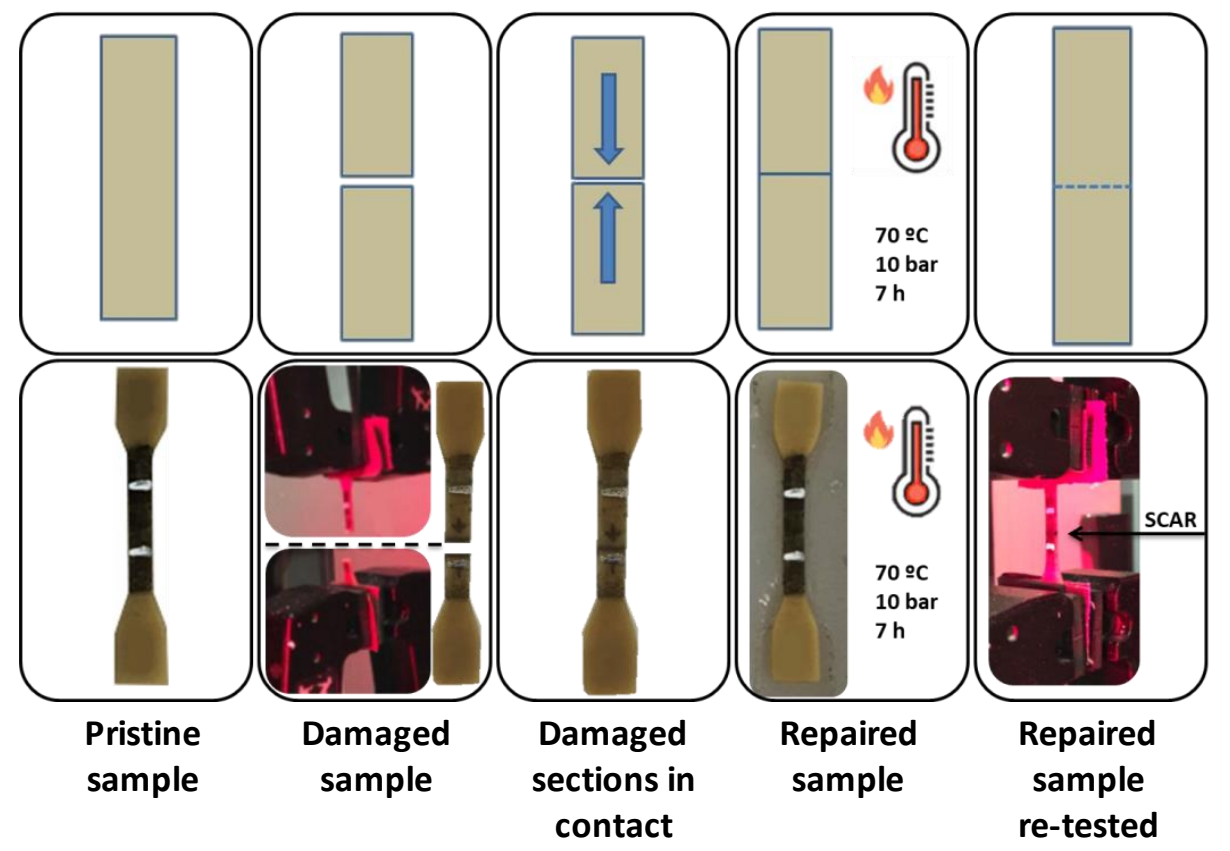

Figure 1. Schematic representation of healing protocol.

The healing efficiency $(\eta)$ was calculated as the ratio between the tensile strength $\left(\sigma_{b}\right)$ of healed and pristine specimens according to equation (1):

$\eta[\%]=\frac{\sigma_{\mathrm{b}}^{\text {healed }}}{\sigma_{\mathrm{b}}^{\text {pristine }}} \times 100$

\section{RESULTS AND DISCUSSION}

\section{Self-healing SBR compounds}

\section{Chemical and mechanical characterization}

Effect of A/S ratio and carbon black content. Three different curing systems were evaluated, varying the accelerant/sulfur ratio $(\mathrm{A} / \mathrm{S})$ in the order: $\mathrm{C} 1(\mathrm{~A} / \mathrm{S}=0.2)<\mathrm{C} 2(\mathrm{~A} / \mathrm{S}=1)<\mathrm{C} 3(\mathrm{~A} / \mathrm{S}=$ 4). The most relevant parameters obtained from the curing curves, such as optimum cure time ( $\left.t_{90}\right)$, minimum torque $\left(\mathrm{M}_{\mathrm{L}}\right)$, maximum torque $\left(\mathrm{M}_{\mathrm{H}}\right)$, extent of cure $\left(\mathrm{M}_{\mathrm{H}}-\mathrm{M}_{\mathrm{L}}\right)$ among others, are summarized in Table 3 and show the well-known fact that an increase of the A/S ratio reduces the length of the sulfur bridges and increases the number of crosslinks.[36-37] Table 3 also compiles the calculated values of crosslinking density based on swelling tests and mechanical properties for the different compounds, showing good agreement with the curing parameters trends. The notorious increase in crosslinking density for $\mathrm{C} 3$ can be ascribed to the highest amount of accelerant. Sulphenamide-type accelerants, due to the homolytic splitting at early stages of vulcanization, are able to form two free rubber radicals which can react with sulfur, thus forming crosslinks. In this way such system, once it has split up, has a self-accelerating or auto-catalytic effect.[37] C2 compounds were further selected due to their higher healing efficiency (as will be discussed in the next section) and 10, 20 and 30phr of carbon black N-330 were added. The accelerating effect of the filler is observed, by decreasing $t_{10}, t_{50}$ and $t_{90}$.[38] The reinforcing effect is as expected, evidenced by the increase in $\mathrm{M}_{\mathrm{H}}$, tensile stress at various 
deformations, tensile strength and crosslinking density, as filler content increases. Tensile curves are provided as Supplementary Information.

Table 3. Curing parameters, crosslinking density, and mechanical properties of SBR compounds.

\begin{tabular}{|c|c|c|c|c|c|c|}
\hline & \multicolumn{6}{|c|}{ Compound } \\
\hline & C1 & $\mathbf{C 2}$ & $\mathbf{C 3}$ & C2-10CB & C2-20CB & C2-30CB \\
\hline \multicolumn{7}{|c|}{ Curing parameters } \\
\hline $\begin{array}{l}\text { Minimum } \\
\text { torque, } \mathrm{M}_{\mathrm{L}} \\
\text { (dN.m) }\end{array}$ & 0.70 & 0.68 & 0.65 & 0.80 & 0.89 & 1.36 \\
\hline $\begin{array}{l}\text { Maximum } \\
\text { torque, } \mathrm{M}_{\mathrm{H}} \\
\text { (dN.m) }\end{array}$ & 2.69 & 3.84 & 6.96 & 5.07 & 5.82 & 7.21 \\
\hline $\begin{array}{l}\text { Extent of cure, } \\
\mathrm{M}_{\mathrm{H}}-\mathrm{M}_{\mathrm{L}} \\
(\mathrm{dN} . \mathrm{m})\end{array}$ & 2.62 & 3.16 & 6.31 & 4.27 & 4.93 & 5.85 \\
\hline $\mathrm{t}_{10}(\min )$ & 11.2 & 13.0 & 11.6 & 6.5 & 5.1 & 4.4 \\
\hline $\mathrm{t}_{50}(\min )$ & 42.9 & 20.6 & 13.6 & 12.9 & 11.6 & 10.8 \\
\hline $\begin{array}{l}\text { Optimum cure } \\
\text { time, } t_{90}(\mathrm{~min})\end{array}$ & 109.1 & 35.8 & 18.9 & 26.4 & 25.9 & 23.7 \\
\hline \multicolumn{7}{|c|}{ Mechanical properties } \\
\hline $\begin{array}{l}\text { Tensile stress at } \\
100 \% \text { strain, } \\
\sigma_{100}(\mathrm{MPa})\end{array}$ & $0.52 \pm 0.01$ & $0.54 \pm 0.03$ & $0.81 \pm 0.01$ & $0.64 \pm 0.04$ & $0.82 \pm 0.02$ & $1.12 \pm 0.01$ \\
\hline $\begin{array}{l}\text { Tensile stress at } \\
300 \% \text { strain, } \\
\sigma_{300}(\mathrm{MPa})\end{array}$ & $0.55 \pm 0.01$ & $0.66 \pm 0.01$ & $1.32 \pm 0.02$ & $0.98 \pm 0.03$ & $1.44 \pm 0.02$ & $2.49 \pm 0.09$ \\
\hline $\begin{array}{l}\text { Tensile stress at } \\
500 \% \text { strain, } \\
\sigma_{500}(\mathrm{MPa})\end{array}$ & $0.62 \pm 0.01$ & $0.80 \pm 0.02$ & $1.99 \pm 0.02$ & $1.59 \pm 0.03$ & $2.45 \pm 0.03$ & $4.47 \pm 0.18$ \\
\hline $\begin{array}{l}\text { Tensile } \\
\text { strength, } \sigma_{b} \\
(\mathrm{MPa})\end{array}$ & $1.48 \pm 0.11$ & $1.34 \pm 0.15$ & $2.29 \pm 0.26$ & $7.83 \pm 0.36$ & $12.60 \pm 0.92$ & $19.10 \pm 0.29$ \\
\hline $\begin{array}{l}\text { Elongation at } \\
\text { break, } \varepsilon_{\mathrm{b}}(\%)\end{array}$ & $1426 \pm 94$ & $924 \pm 70$ & $561 \pm 53$ & $1457 \pm 37$ & $1477 \pm 30$ & $1375 \pm 13$ \\
\hline $\begin{array}{l}\text { Crosslinking } \\
\text { density, } v \\
\text { x } 10^{-4}(\mathrm{~mol} / \mathrm{g})\end{array}$ & $1.92 \pm 0.39$ & $7.58 \pm 0.72$ & $33.94 \pm 0.32$ & $10.20 \pm 0.26$ & $10.32 \pm 0.14$ & $14.23 \pm 0.18$ \\
\hline
\end{tabular}

Effect of TESPT content. Selected C2 compounds were chemically modified by silane coupling agent TESPT $(2.5,5$ and $10 \mathrm{phr})$. As shown in Table 4, TESPT has a plasticizing effect at the early stages of the vulcanization reducing the viscosity of the compound, expressed as a decrease in $\mathrm{M}_{\mathrm{L}}$. An increase in $\mathrm{M}_{\mathrm{H}}$ and in the extent of cure $\left(\mathrm{M}_{\mathrm{H}}-\mathrm{M}_{\mathrm{L}}\right)$ is also observed, indicating relatively more restrained matrix resulting from improved interaction between the blend components. The improved interaction between the blend components is also indicated by the increase in the crosslinking density of the matrix. This is attributed to the fact that TESPT 
contains 4 sulfur atoms on its molecule acting as accelerator and sulfur donor to the rubber compound.[39] Silane coupling agent is a bifunctional compound composed of two functionally active end groups, i.e., the readily hydrolysable alkoxy group and the organo-functional group. The latter, which is relatively non-polar, is more compatible with rubbers and also can participate in the sulfur vulcanization to form chemical linkages with the rubber matrix. The homolytic cleavage of S-S bonds of TESPT takes place forming free radicals at the curing temperature. These radicals may then combine with rubber chains and free sulfur (See Supplementary Information). Adding TESPT also reduces $\mathrm{t}_{10}$, demonstrating the accelerating effect of the coupling agent on the onset of vulcanization. Nonetheless, it has a decelerating effect further in the vulcanization process, resulting in longer curing times $\left(t_{90}\right)$ as silane content increases.[40-42] With regard to mechanical properties, C2-TESPT compounds yield a decrease in elongation at break, and an increase in tensile stress at all strains and at break compared to the control (C2), in accordance with curing characteristics.

Table 4. Curing parameters, crosslinking density, and mechanical properties of SBR-TESPT compounds.

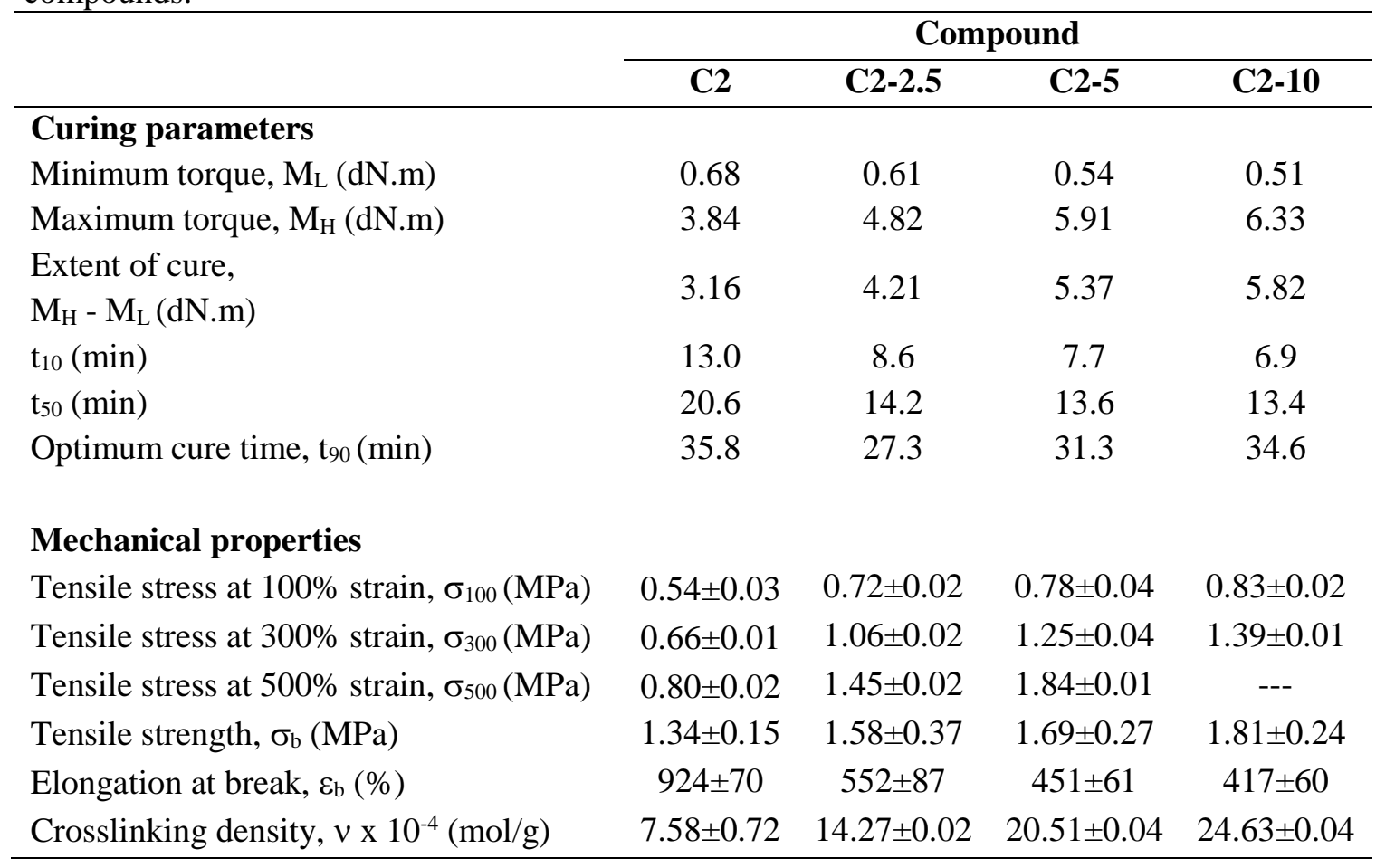

The improved rubber-TESPT network can also be corroborated by the smooth and uniform appearance of the rubber matrix (see Figure $2 \mathrm{a}$ and $\mathrm{b}$ ) and by the appearance of characteristic absorption bands in the FTIR spectra, as shown in Figure 3: the Si-O-Si stretching observed at $1169 \mathrm{~cm}^{-1}$, which is accompanied by the absorbencies at $1650-1550$ and $3500 \mathrm{~cm}^{-1}$ assigned to $\mathrm{Si}-\mathrm{OH}$. Stretching of -S-C- bonds can be followed at wavenumbers around $1160-990 \mathrm{~cm}^{-1}$, but it partially overlaps with siloxane peaks. 

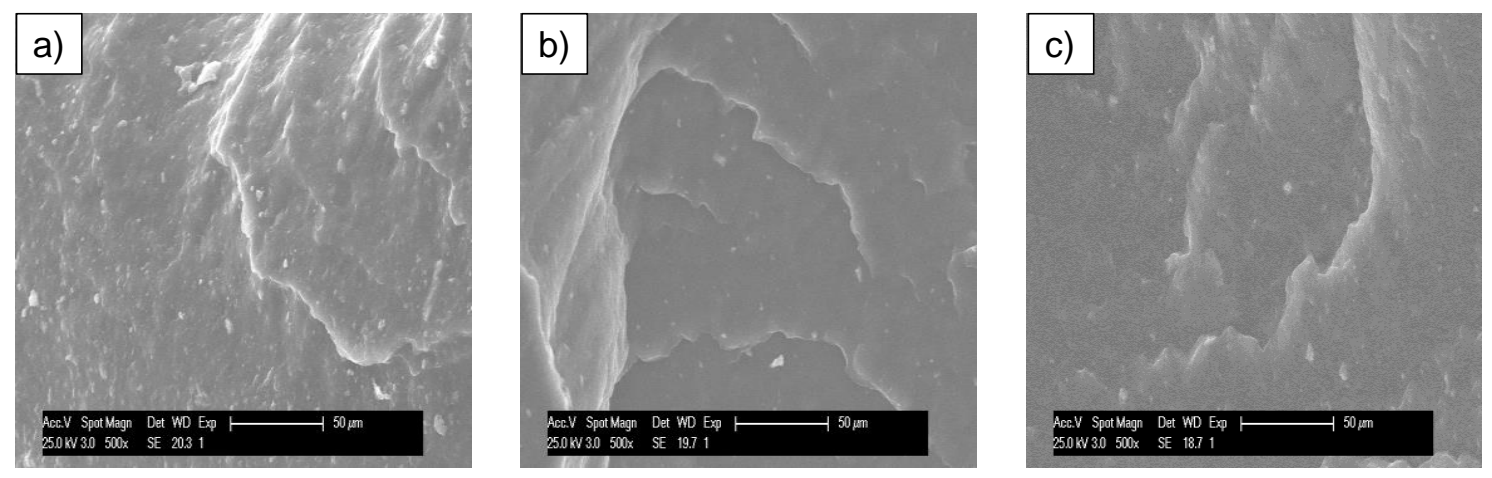

Figure 2. SEM images of: a) C2, b) C2-5 and c) C2-5-GTR1 compounds.

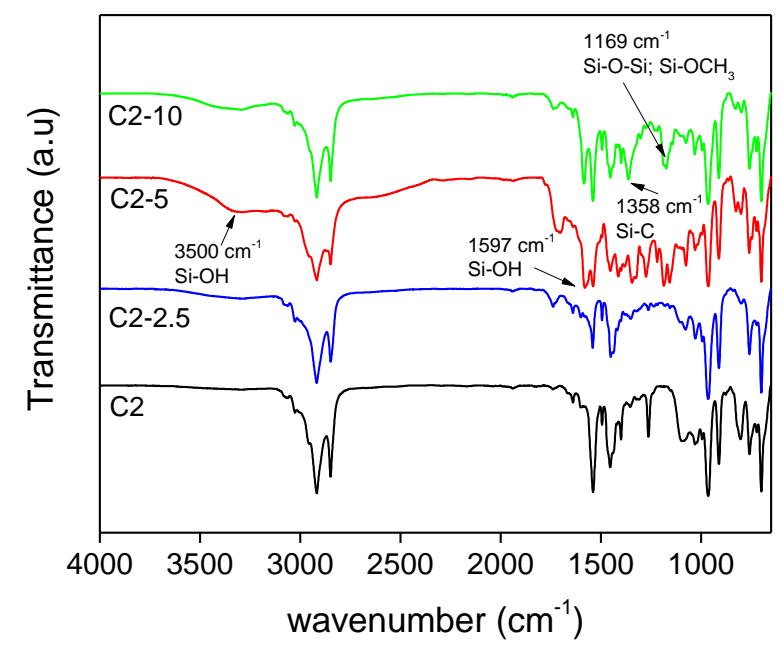

Figure 3. FT-IR spectra of SBR compounds with different content of TESPT.

\section{Mechanical healing}

Effect of A/S ratio and carbon black content. Figure 4a) shows tensile strength values of pristine and healed SBR compounds with different A/S ratio. Healed samples are considered specimens in which the restoration of the damaged interface and, thus, mechanical integrity is partially achieved. The quantification of the mechanical healing efficiency is shown in Figure $4 \mathrm{~b}$ ). Interestingly, there seems to be a correlation between both plots: lower mechanical performance rubber systems show higher healing capability, putting in evidence the compromise between mechanical properties and healing.[10] The healing efficiency increases in the order: C3 $(\mathrm{A} / \mathrm{S}=4)<\mathrm{C} 1(\mathrm{~A} / \mathrm{S}=0.2)<\mathrm{C} 2(\mathrm{~A} / \mathrm{S}=1) . \mathrm{C} 3$ is a very stable and highly sulfur crosslinked network, making the restoration of the interface less possible under the studied healing conditions; while the less crosslinked networks resulting from $\mathrm{C} 1$ and $\mathrm{C} 2$ compounds allow for a substantially higher mobility, which favors rubber chain interdiffusion and the rearrangement of broken reversible bonds at the healed interface. $\mathrm{T}_{\mathrm{g}}$ values reported as Supplementary Information also support this behavior. Short-range interactions due to entanglements between dangling chains are considered to take place during the initial stage of healing.[18] Followed by the temperature-triggered opening of di- and poly-sulfide bonds (present in the chemical structure of sulfur-cured networks, see Supplementary Information), which provides higher chain mobility for the system and allows the macroscopic flow required to close the cut.[35] The disulfide (and polysulfide) exchange reactions are thus regarded as the main contributor to 
the restoration of the mechanical strength; it is presumed that the underlying healing mechanism is determined by the temperature-driven formation of sulfur radicals that bond to each other once the energetic stimulus is removed to form a new disulfide bridge across the damaged interface.[7, 10, 43-45] It has also been reported that higher healing can be achieved by replacing disulfide bonds with tetrasulfides, as the stability of the S-S bridges decreases by increasing the number of sulfur atoms beyond two.[35, 46] It would thereof be expected that the lower A/S ratio compounds ( $\mathrm{C} 1$ and $\mathrm{C} 2$ ) with longer length sulfur bridges lead to higher healing. Thus, a combination between lower crosslinking density and lower $\mathrm{A} / \mathrm{S}$ ratio seems to be the reason for the highest healing achieved by $\mathrm{C} 1$ and $\mathrm{C} 2$.
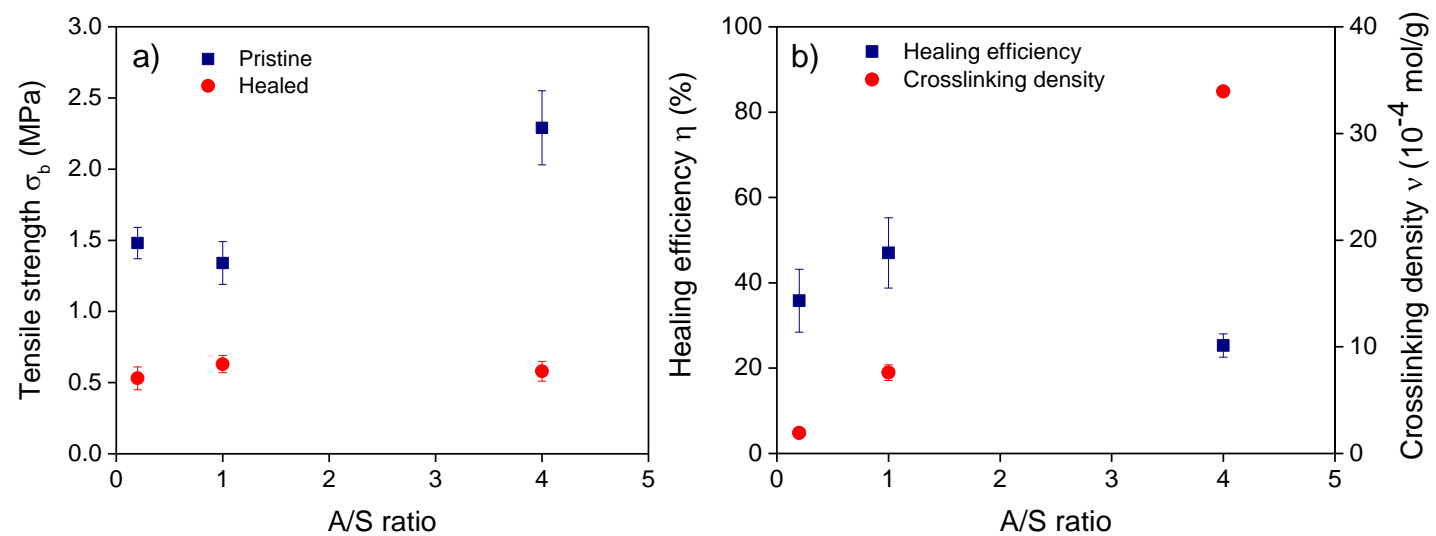

Figure 4. a) Tensile strength of pristine and healed samples and b) Healing efficiency and crosslinking density, as function of $\mathrm{A} / \mathrm{S}$ ratio.

The same opposing correlation between mechanical performance and healing efficiency is seen when carbon black (CB) content varies. The presence of this reinforcing filler severely affects healing; no recovery is achieved with filler content as low as 10phr, as seen in Figure 5. All facts suggest that higher mobility restrictions, due to the presence of carbon black and increase in crosslinking density, come into play during the thermal healing treatment. This result also puts in evidence the trade-off between repairability and mechanical properties and the need of alternative fillers that can improve healing capability without detriment of the structural integrity or vice-versa.

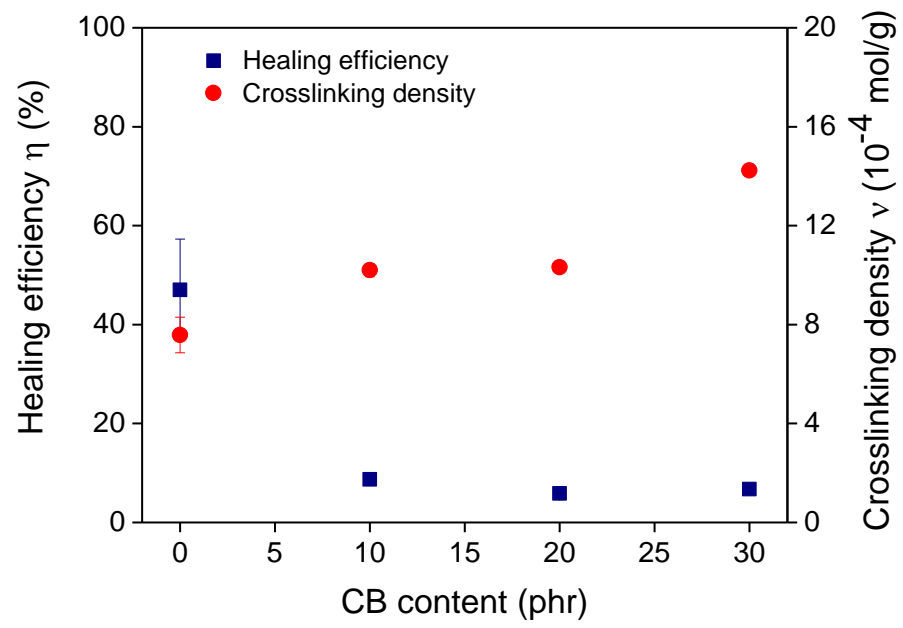

Figure 5. Healing efficiency and crosslinking density of SBR compounds, as function of carbon black content. 
Effect of TESPT content. The effect of TESPT on the healing capability of C2 compounds was also evaluated. The intention of adding TESPT was to improve the mechanical performance, as well as to increase repairability. Silane based coupling agents have been used in different networks as crosslinking agents favoring healing due to disulfide exchange reactions thanks to the presence of a tetrasulfide bond in their structure.[35, 47] The results plotted in Figure 6 show that, as previously mentioned, mechanical strength improves in presence of TESPT. Interestingly, healing efficiency is not significantly affected by the inclusion of TESPT; it remains close to that of the $\mathrm{C} 2$ control compound (with no TESPT) since all values are in the range of 40 to $50 \%$ of recovery. Therefore, a positive trade-off between mechanical and healing performance is achieved, contrary to the above mentioned results for highly crosslinked systems (C3) or for CB filled compounds. It can then be presumed that the tetrasulfides present in the structure of TESPT participate in the temperature triggered healing mechanism, combining with broken rubber chain radicals as well as acting as crosslinking points. SBR compounds present a wide set of mechanical properties according to the curing system (amount of sulfur, type of accelerant, accelerant/sulfur ratio), curing temperature, and presence of fillers, among others. For instance, SBR tensile strength has been reported to vary from $2 \mathrm{MPa}$ [48-49], to 13MPa [50]. Hence, our self-healable SBR compounds, which show tensile strength values of $1.4-2.3$ $\mathrm{MPa}$, are similar to those reported in the literature, without adding any filler and with a lower amount of sulfur than what is normally used.
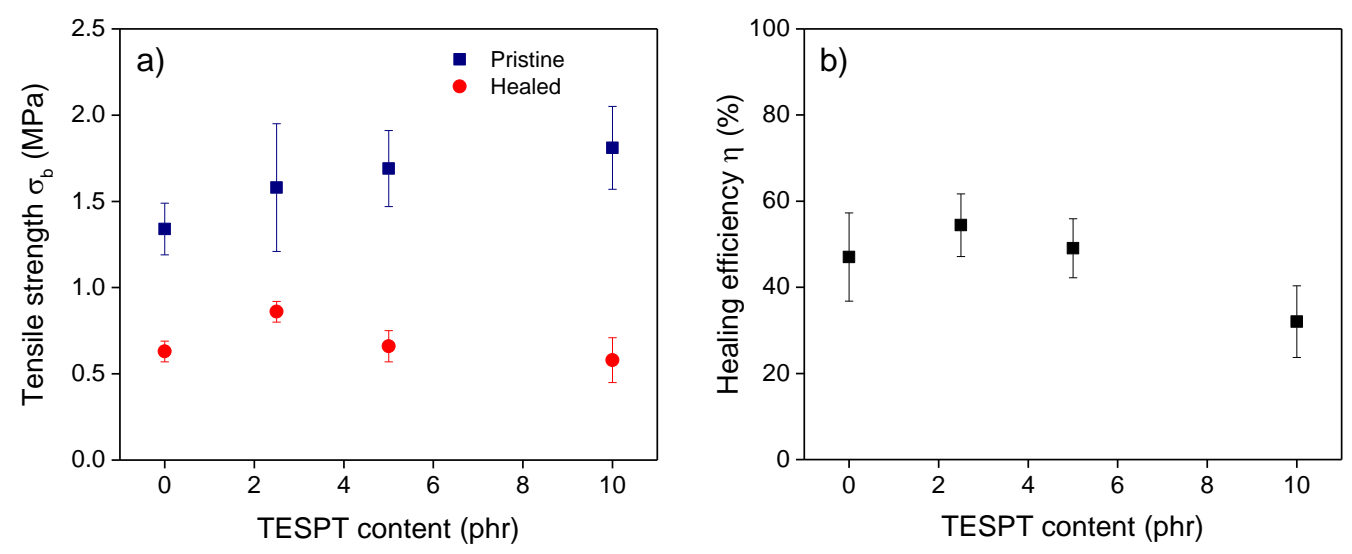

Figure 6. a) Tensile strength of pristine and healed samples and b) Healing efficiency, as function of TESPT content.

\section{Using GTR as alternative filler in self-healing SBR compounds}

\section{Characterization of GTR}

4 different batches of ground tire rubber (GTR) obtained by ambient grinding of used tires (combination of passenger car and truck tires of unknown composition) with different particle size were supplied by Signus, as shown in Figure 7. 


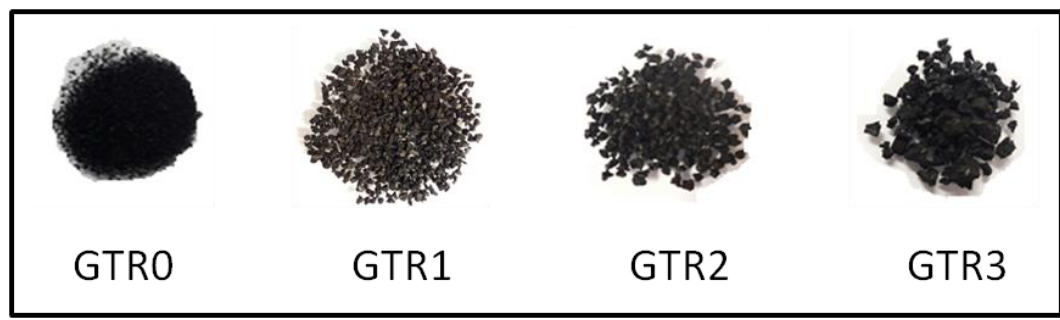

Figure 7. Photographs of as-received GTR batches with different particle size.

The final properties of rubber composites, using GTR as filler, depend on both the type of rubber matrix incorporated with GTR and the adhesion between GTR and the matrix.[27] Thus, understanding of the chemical nature of GTR prior to its incorporation in a polymeric matrix is required. As can be seen in Table 5, all batches have very similar density values and glass transition temperature $\left(\mathrm{T}_{\mathrm{g}}\right)$, as calculated by DSC, regardless their composition.

Table 5. Physical properties of as-received GTR batches.

\begin{tabular}{cccc}
\hline GTR & Average particle size $(\mathbf{m m})^{\mathbf{1}}$ & Density $\left(\mathbf{g} / \mathbf{c m}^{\mathbf{3}}\right)$ & $\mathbf{T}_{\mathbf{g}}\left({ }^{\circ} \mathbf{C}\right)$ \\
\hline GTR0 & $<0.8$ & $1.12 \pm 0.01$ & -57 \\
GTR1 & $0.8-2$ & $1.12 \pm 0.01$ & -56 \\
GTR2 & $2-4$ & $1.11 \pm 0.03$ & -57 \\
GTR3 & $4-8$ & $1.12 \pm 0.02$ & -58 \\
\hline \multicolumn{2}{r}{${ }^{1}$ Value reported by the supplier } &
\end{tabular}

TGA analysis was done to quantify the relative ratios of rubbers, carbon black and ash present in GTR. One can assume that GTR batches were composed of various blends of NR, SBR and $\mathrm{BR}$ as the major polymeric components. Other additives expected to be present (e.g. zinc oxide, stearic acid, accelerator and sulfur), typically included in a tire compound, were not considered in this research. Weight losses at the temperatures of degradation of the rubbers, carbon black and char residue are listed in Table 6 and a representative TGA/dTGA curve is shown in Figure 8.

Table 6. \% weight loss and degradation temperature $\left(\mathrm{T}_{\mathrm{d}}\right)$ of as-received GTR batches.

\begin{tabular}{ccccccccc}
\hline GTR & $\begin{array}{c}\text { Initial } \\
\text { loss }\end{array}$ & \multicolumn{2}{c}{ NR } & \multicolumn{2}{c}{ SBR/BR } & & CB & $\begin{array}{c}\text { Char } \\
\text { residue }\end{array}$ \\
\cline { 2 - 10 } & $\boldsymbol{\%}$ & $\%$ & $\begin{array}{c}\mathbf{T}_{\mathbf{d}} \\
\left({ }^{\mathbf{0}} \mathbf{C}\right)\end{array}$ & $\boldsymbol{\%}$ & $\begin{array}{c}\mathbf{T}_{\mathbf{d}} \\
\left({ }^{\mathbf{C}} \mathbf{C}\right)\end{array}$ & $\boldsymbol{\%}$ & $\begin{array}{c}\mathbf{T}_{\mathbf{d}} \\
\left({ }^{\mathbf{}} \mathbf{C}\right)\end{array}$ & $\boldsymbol{\%}$ \\
\hline GTR0 & 5.38 & 34.40 & 402.8 & 24.98 & 417.7 & 30.39 & 658.5 & 4.57 \\
GTR1 & 4.71 & 34.99 & 403.3 & 24.31 & 420.9 & 30.29 & 661.9 & 5.66 \\
GTR2 & 4.89 & 35.46 & 402.7 & 23.93 & 424.4 & 30.92 & 662.5 & 4.73 \\
GTR3 & 5.14 & 32.19 & 402.9 & 29.19 & 415.5 & 30.68 & 658.9 & 5.09 \\
\hline
\end{tabular}




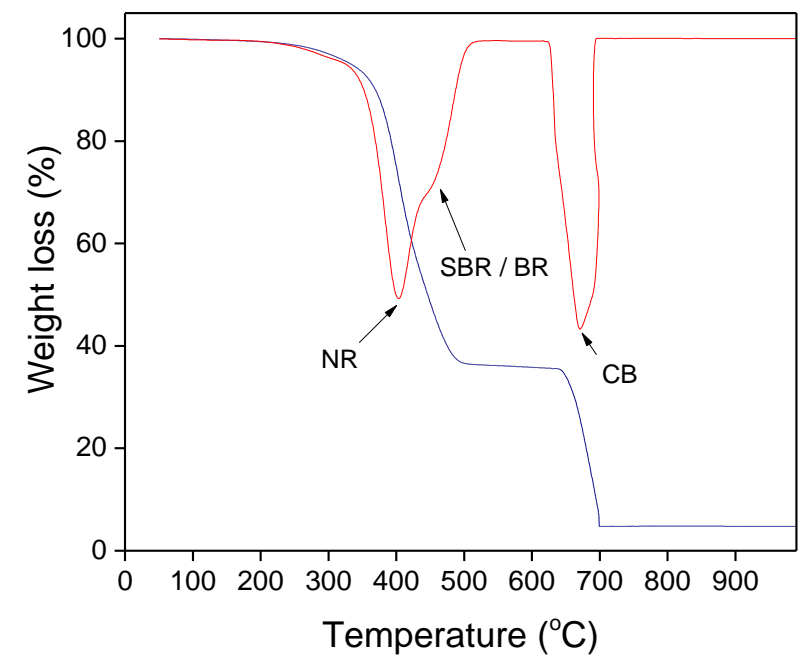

Figure 8. TGA/dTGA curves of GTR1.

Major areas of weight loss are observed between 300 and $500^{\circ} \mathrm{C}$ in all the samples. These losses took place in an inert atmosphere, producing two peaks in each curve. The first peak starting at around $330^{\circ} \mathrm{C}$ is indicative of a particular rubber, while the second peak observed at higher temperature, starting around $420^{\circ} \mathrm{C}$, is strongly indicative of another rubber. The third weight loss above $620^{\circ} \mathrm{C}$ in presence of oxygen is due to carbon black. The degradation temperatures were strongly directive towards assuming the lower temperature for NR and the higher temperature for SBR or BR or a mixture of the two;[51-52] SBR and BR have overlapping degradation temperature. The weight percentages of the rubbers were converted into phr (parts per hundred parts of rubber) as usually expressed in the rubber industry (see Table 7). The composition of all the samples studied here seems very similar independently of the batch: 55 phr NR, $45 \mathrm{phr}$ SBR/BR and $50 \mathrm{phr} \mathrm{CB}$, in average.

Table 7. TGA results showing rubber compound composition expressed in phr.

\begin{tabular}{cccc} 
GTR & NR & SBR/BR & CB \\
\hline GTR0 & 57.9 & 42.1 & 51.2 \\
GTR1 & 59.0 & 41.0 & 51.1 \\
GTR2 & 59.7 & 40.3 & 52.1 \\
GTR3 & 52.4 & 47.6 & 50.0 \\
\hline
\end{tabular}

ATR FT-IR studies were also done as shown in Figure 9. As expected, all four spectra look very similar. A slight difference could be seen in the spectrum of GTR1, since two characteristics peaks of SBR appear (the $\mathrm{C}_{-} \mathrm{CH}_{2}$ stretching from trans-butadiene comonomer at $969 \mathrm{~cm}^{-1}$ and the aromatic $\mathrm{C}-\mathrm{H}$ stretching from styrene comonomer at $\left.3045 \mathrm{~cm}^{-1}\right)$. The fact that all 4 batches of GTR (coming from 4 different random sources) have similar properties is a promising result for the recycling and reuse of discarded tires. More than the chemical nature of GTR what seems to govern the final properties, as will be discussed next, is the good interaction and compatibility between the rubber powder and a selected matrix. From the 4 batches analyzed, GTR1 was selected as the GTR to be included as alternative filler in the SBR compound. 


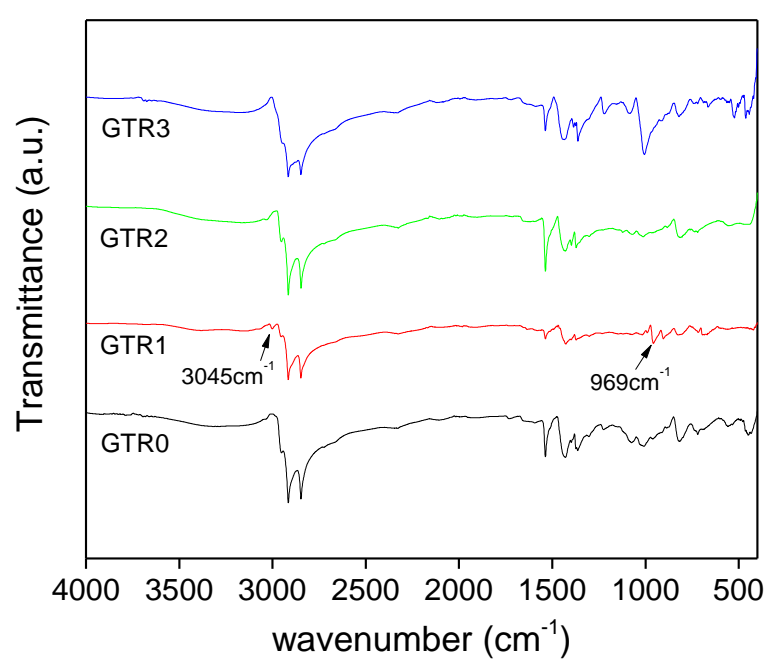

Figure 9. ATR FT-IR spectra of different GTR batches.

GTR1 was further cryogenically grounded according to a grinding protocol previously evaluated. Further details on various grinding protocols will be given in an upcoming paper. Figure 10 shows the particle size distribution of GTR1. Average particle size of cryo-grounded rubber (cryo-GTR1) is of $157 \mu \mathrm{m}$, corroborating the size reduction with respect to the asreceived batch $(1519 \mu \mathrm{m})$. The improvement in mechanical properties derived from particle size reduction can be seen in the stress-strain curves supplied as Supplementary Information. Morphology of rubber powder as observed by SEM is shown in Figure 11. The presence of aggregates formed by smooth-grained individual particles of $\sim 5 \mu \mathrm{m}$ is observable. The cryogrounded rubber cryo-GTR1 from now on named simply GTR1 was added to the SBR compounds.

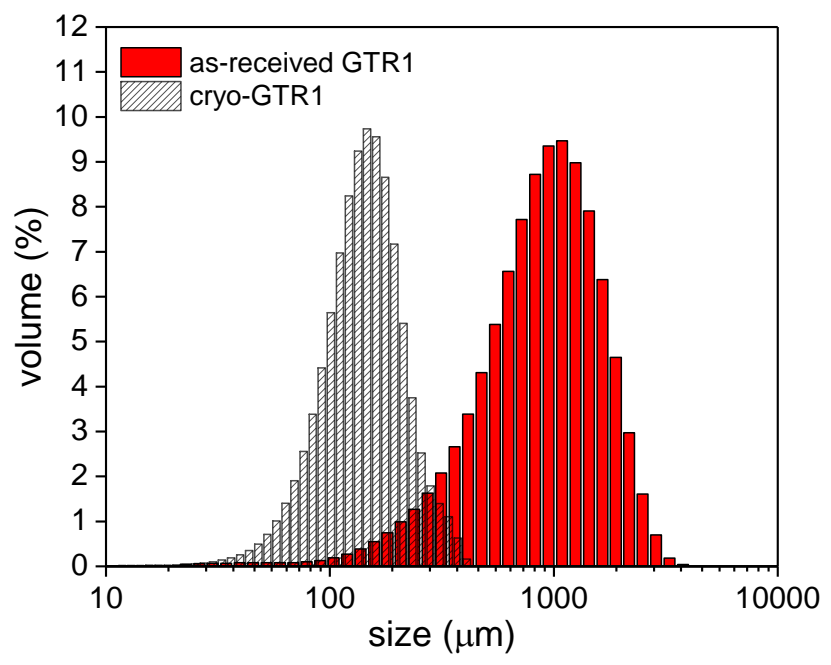

Figure 10. Particle size distribution of as-received and cryo-grounded GTR1. 

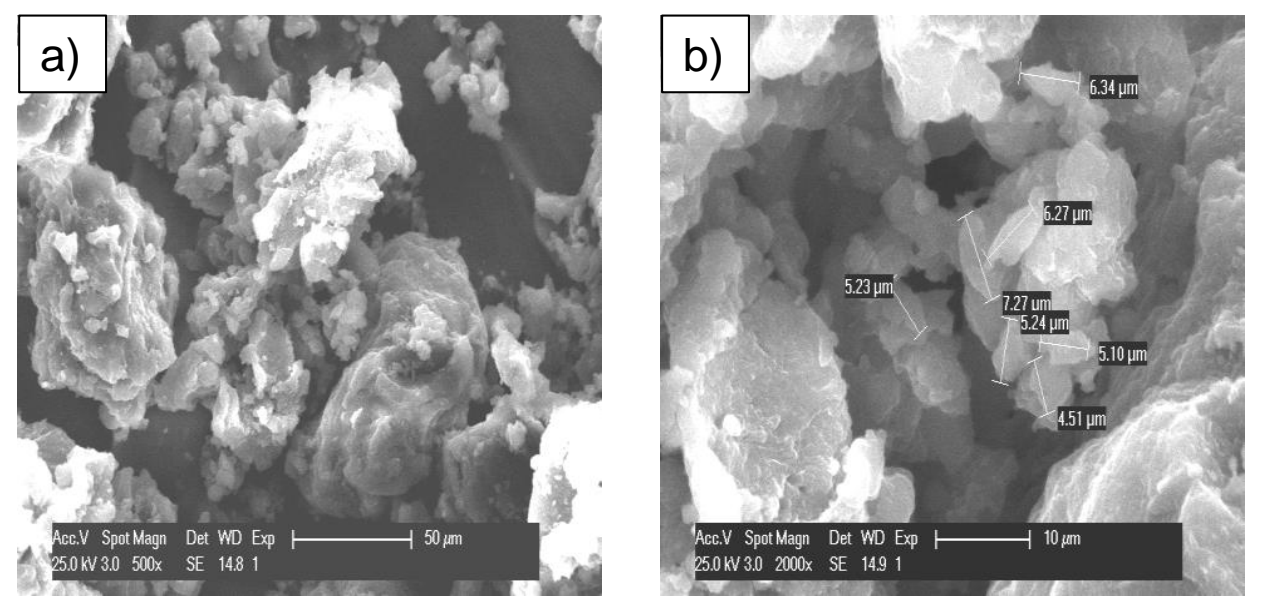

Figure 11. SEM micrographs of cryo-GTR1 at different magnifications: a) 500x, b) 2000x showing individual particle size.

\section{Effect of GTR on mechanical properties and healing}

Self-healing C2-GTR1 compounds were prepared with and without TESPT (see Table 2). Fixed contents of GTR1 (10phr) and TESPT (5phr) were selected. Lamminmaki et al.[53] in their work found that the incorporation of GTR as filler in rubber blends would be limited to $15 \mathrm{wt} . \%$ to have balanced properties. The extent of cure decreases when GTR1 is present (see Table 8). This is attributed to the fact that GTR1 is already partially crosslinked and, hence, there are relatively less reaction sites available for further crosslinking.[42] However, the improved GTR1-matrix interactions when a silane coupling agent is present compensate this, increasing the extent of cure and the crosslinking density. From the data shown in Table 8 and in Figure 12 , it is also clear that GTR1 acts as reinforcing filler increasing by $50 \%$ the tensile strength, but not as efficient as the rise obtained (466\%) with equal amount of carbon black (C2-10CB). Some authors claim improvement in mechanical properties when GTR is incorporated into SBR, thanks to the presence of carbon black in the GTR.[54] Contradictory, other studies reported elsewhere[55-57] claim that migration of sulfur from the rubber matrix to the molecules of the GTR and migration of accelerants from the GTR to the rubber take place, deteriorating mechanical performance due to a decrease in crosslinking density. In this research, although crosslinking density drops from $7.58 \pm 0.72 \times 10^{-4} \mathrm{~mol} / \mathrm{g}$ for $\mathrm{C} 2$ to $4.58 \pm 0.12 \times 10^{-4} \mathrm{~mol} / \mathrm{g}$ for C2-GTR1, the prevailing factor for achieving better mechanical properties seems to be the carbon black incorporated in the GTR, which lies around 30\% as previously determined.

Table 8. Curing parameters, crosslinking density, and mechanical properties of C2-GTR1 compounds.

\begin{tabular}{lccc}
\hline & \multicolumn{3}{c}{ Compound } \\
\cline { 2 - 4 } & C2 & C2-GTR1 & C2-5-GTR1 \\
\hline Curing parameters & 0.68 & 0.64 & 0.54 \\
Minimum torque, $\mathrm{M}_{\mathrm{L}}(\mathrm{dN} . \mathrm{m})$ & 3.84 & 3.24 & 5.91 \\
Maximum torque, $\mathrm{M}_{\mathrm{H}}(\mathrm{dN} . \mathrm{m})$ & 3.16 & 2.60 & 5.37 \\
Extent of cure, $\mathrm{M}_{\mathrm{H}}-\mathrm{M}_{\mathrm{L}}(\mathrm{dN} . \mathrm{m})$ & 13.0 & 7.5 & 7.7 \\
$\mathrm{t}_{10}(\min )$ & 20.6 & 13.9 & 13.6 \\
$\mathrm{t}_{50}(\min )$ & 35.8 & 28.7 & 31.3 \\
Optimum cure time, $\mathrm{t}_{90}(\mathrm{~min})$ &
\end{tabular}




\section{Mechanical properties}

Tensile stress at $100 \%$ strain, $\sigma_{100}(\mathrm{MPa})$

Tensile stress at $300 \%$ strain, $\sigma_{300}(\mathrm{MPa})$

$0.54 \pm 0.03 \quad 0.58 \pm 0.01$

$0.79 \pm 0.01$

Tensile stress at $500 \%$ strain, $\sigma_{500}(\mathrm{MPa})$

$0.66 \pm 0.01 \quad 0.69 \pm 0.01$

$1.26 \pm 0.02$

Tensile strength, $\sigma_{\mathrm{b}}(\mathrm{MPa})$

$0.80 \pm 0.02 \quad 0.89 \pm 0.01$

$1.98 \pm 0.01$

Elongation at break, $\varepsilon_{\mathrm{b}}(\%)$

$1.34 \pm 0.15 \quad 2.10 \pm 0.13$

$2.51 \pm 0.06$

Crosslinking density, $v$ x $10^{-4}(\mathrm{~mol} / \mathrm{g})$
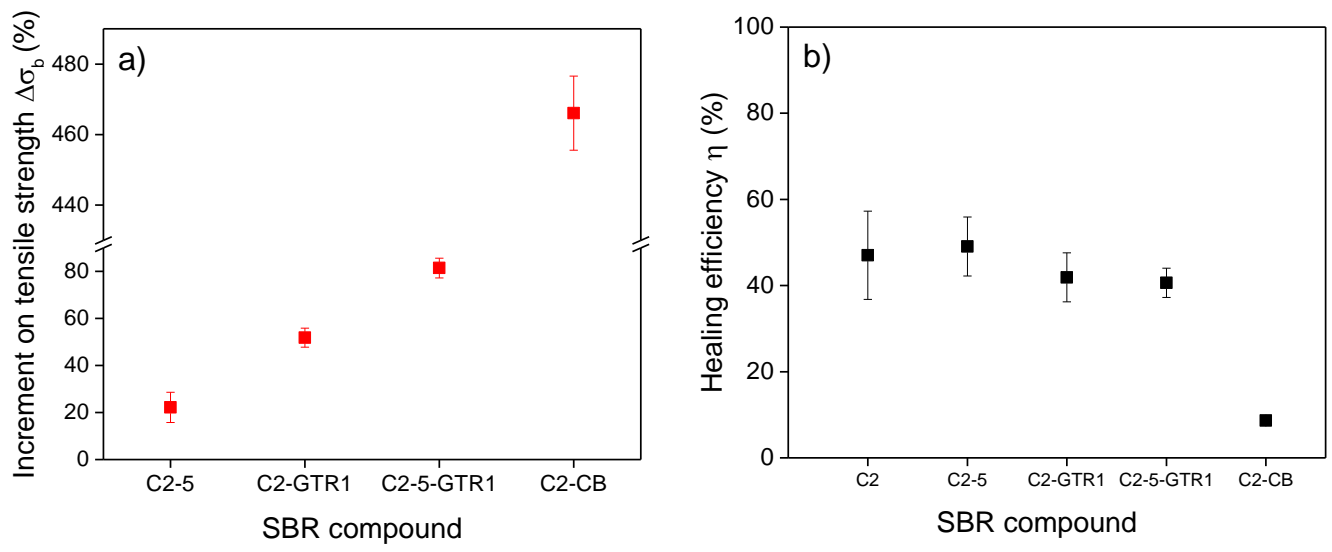

Figure 12. a) Increment in tensile strength with respect to $C 2$ and b) healing efficiency, of SBR compounds.

When TESPT is added (C2-5-GTR1 compound), the tensile strength improves significantly up to $80 \%$. This superior reinforcement capacity could be due to the rigid covalent bonding of the tetra-functional silane between GTR1 and SBR matrix which results in a stiff interphase transferring stress to GTR1, and to the ability of active crosslinking sites in GTR1 and elemental sulfur in TESPT participating in the crosslinking process.[58] This shows the importance of an effective covalent bonding between active sites in GTR and matrix in controlling mechanical properties as well as stabilizing the rubber network. These chemical bonds will also result in enhanced interfacial adhesion between the GTR and the rubber matrix. SEM images of the C2-5-GTR1 compound can be seen in Figure 2c) showing a smooth surface and uniform and homogeneous dispersion of the TESPT-GTR1 in the SBR matrix.

Figure 12 also shows the healing efficiency of SBR-GTR1 compounds with and without TESPT. The material self-healing response is related to the presence of disulfide bonds as schematically shown in Figure 13. Thanks to the mechanical shearing forces during the cryogrinding process of GTR1, scission of S-S crosslink bonds can occur forming disulfide radicals.[59] The homolytic cleavage of S-S bonds of TESPT can also take place during the occurrence of the mechanical damage. At the healing temperature these radicals, both from GTR1 and TESPT, combine with broken polymer chain radicals as well as recombine with other disulfide radicals. The chain interdiffusion facilitated by the increased dynamics (openclose) of the disulfide bridges at the healing temperature allows re-establishing the chemical bonding across the damaged surface and thus leads to the partial recovery of the mechanical properties.[10] Very small variations on healing efficiency are seen with regard to C2 control compound, thus it is not possible to differentiate the individual contribution from the GTR and from TESPT. Nonetheless, the improved mechanical properties of the C2-5-GTR1 compound 
without detriment on the healing capability allows us to conclude that the addition of GTR as filler in presence of a silane coupling agent defeats the challenge of obtaining a crosslinked network with reversible covalent bonds that can infer healing capabilities to the rubber as well as good mechanical properties.

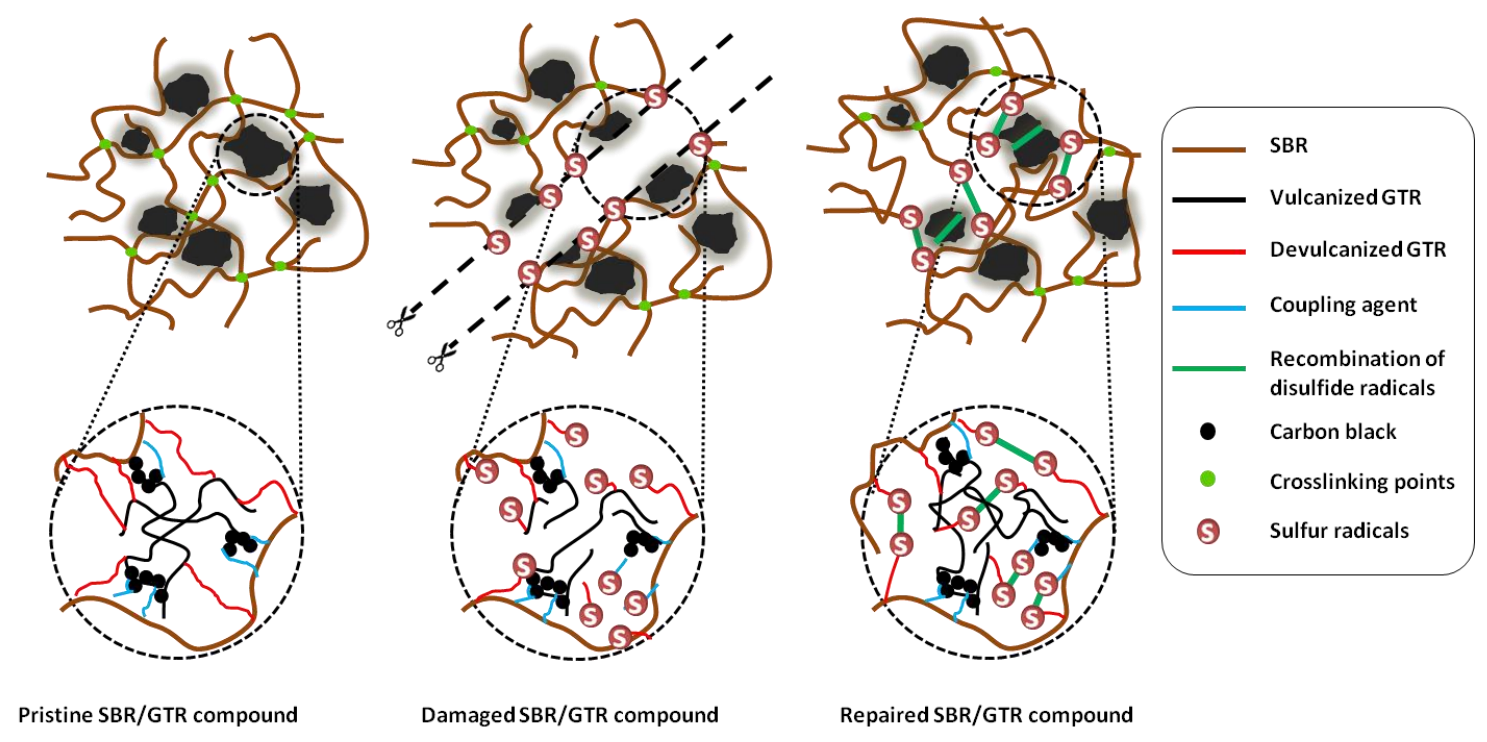

Figure 13. Schematic representation of healing mechanism in SBR-GTR compounds.

\section{CONCLUSIONS}

The aim of the present work was to design SBR compounds with sustainable characteristics. This sustainability was to be achieved by the inclusion of ground tire rubber (GTR) as alternative filler and by the ability to repair damage (i.e. self-healing) and thus extend the service lifetime of the rubber.

Different vulcanization recipes were evaluated, as well as the presence of a silane-based coupling agent. It was found that the semi-efficient vulcanization system gives the best balance between tensile strength and healing and that a coupling agent improves even more the mechanical performance with no detriment on healing.

A comparison to carbon black filled SBR compounds was also made, resulting in an expected divergent correlation between mechanical performance and healing efficiency. An increase in reinforcing filler content, and thus in crosslinking density, severely affected healing; no recovery was achieved with carbon black content as low as 10phr. Equivalent amount of GTR was assessed for the first time as potential filler in self-healing SBR compounds. The lower improvement in mechanical properties did not allow considering it as comparable reinforcing filler. However, when a silane coupling agent was added to the SBR-GTR compounds, tensile strength increased up to $80 \%$. This increase was obtained with no detriment in healing efficiency, which was maintained around $50 \%$. In conclusion, SBR compounds filled with ground tire rubber and in presence of a coupling agent offer a potential versatility to self-healing applications, defeating the challenge of reaching simultaneously good repairability and good mechanical performance. Future work will continue with the aim of enhancing healing behavior. 


\section{SUPPLEMENTARY INFORMATION}

S1. Tensile curves of SBR compounds; S2. Schematic reaction of TESPT with SBR; S3. Tg values obtained by DSC; S4. Characteristic Raman and NMR spectrum of sulfur-cured SBR compounds.

\section{ACKNOWLEDGEMENTS}

M. Hernández acknowledges the Ministry of Economics and Competitiveness of Spain for a research contract (MAT2015-73392-JIN). The authors also acknowledge Signus for providing the ground tire rubber and C. Chirico (Carlos III University, Madrid) for the particle size distribution measurements.

\section{REFERENCES}

1. Garcia, S. J., Effect of Polymer Architecture on the Intrinsic Self-Healing Character of Polymers. Eur. Polym. J. 2014, 53, 118-125.

2. Cordier, P.; Tournilhac, F.; Soulie-Ziakovic, C.; Leibler, L., Self-Healing and Thermoreversible Rubber from Supramolecular Assembly. Nature 2008, 451 (7181), 977-980.

3. Yamaguchi, M.; Ono, S.; Terano, M., Self-Repairing Property of Polymer Network with Dangling Chains. Mater. Lett. 2007, 61 (6), 1396-1399.

4. Lafont, U.; van Zeijl, H.; van der Zwaag, S., Influence of Cross-Linkers on the Cohesive and Adhesive Self-Healing Ability of Polysulfide-Based Thermosets. ACS Appl. Mater. Interfaces 2012, 4 (11), 6280-6288.

5. $\quad$ Schuessele, A. C.; Nuebling, F.; Thomann, Y.; Carstensen, O.; Bauer, G.; Speck, T.; Muelhaupt, R., Self-Healing Rubbers Based on Nbr Blends with Hyperbranched Polyethylenimines. Macromol. Mat. Eng. 2012, 297 (5), 411-419.

6. Rahman, M. A.; Sartore, L.; Bignotti, F.; Di Landro, L., Autonomic Self-Healing in Epoxidized Natural Rubber. ACS Appl. Mater. Interfaces 2013, 5 (4), 1494-1502.

7. Xiang, H. P.; Qian, H. J.; Lu, Z. Y.; Rong, M. Z.; Zhang, M. Q., Crack Healing and Reclaiming of Vulcanized Rubber by Triggering the Rearrangement of Inherent Sulfur Crosslinked Networks. Green Chem. 2015, 17 (8), 4315-4325.

8. Trovatti, E.; Lacerda, T. M.; Carvalho, A. J. F.; Gandini, A., Recycling Tires? Reversible Crosslinking of Poly(Butadiene). Adv. Mater. 2015, 27 (13), 2242-2245.

9. Bai, J.; Li, H.; Shi, Z. X.; Yin, J., An Eco-Friendly Scheme for the Cross-Linked Polybutadiene Elastomer Via Thiol-Ene and Diels-Alder Click Chemistry. Macromolecules 2015, 48 (11), 3539-3546.

10. Hernández, M.; Grande, A. M.; Dierkes, W.; Bijleveld, J.; van der Zwaag, S.; García, S. J., Turning Vulcanized Natural Rubber into a Self-Healing Polymer: Effect of the Disulfide/Polysulfide Ratio. ACS Sustain. Chem. Eng. 2016, 4 (10), 5776-5784.

11. Hernández, M.; Grande, A. M.; van der Zwaag, S.; Garcia, S. J., Monitoring Network and Interfacial Healing Processes by Broadband Dielectric Spectroscopy: A Case Study on Natural Rubber. ACS Appl. Mater. Interfaces 2016, 8 (16), 10647-56.

12. Imbernon, L.; Norvez, S., From Landfilling to Vitrimer Chemistry in Rubber Life Cycle. Eur. Polym. J. 2016, 82, 347-376.

13. Xiang, H. P.; Rong, M. Z.; Zhang, M. Q., Self-Healing, Reshaping, and Recycling of Vulcanized Chloroprene Rubber: A Case Study of Multitask Cyclic Utilization of Cross-Linked Polymer. ACS Sustain. Chem. Eng. 2016, 4 (5), 2715-2724.

14. Xu, C.; Huang, X.; Li, C.; Chen, Y.; Lin, B.; Liang, X., Design of "Zn2+ SaltBondings" Cross-Linked Carboxylated Styrene Butadiene Rubber with Reprocessing and Recycling Ability Via Rearrangements of Ionic Cross-Linkings. ACS Sustain. Chem. Eng. 2016, 4 (12), 6981-6990. 
15. Susa, A.; Bose, R. K.; Grande, A. M.; van der Zwaag, S.; Garcia, S. J., Effect of the Dianhydride/Branched Diamine Ratio on the Architecture and Room Temperature Healing Behavior of Polyetherimides. ACS Appl. Mater. Interfaces 2016, 8 (49), 34068-34079.

16. Xu, C.; Cao, L.; Lin, B.; Liang, X.; Chen, Y., Design of Self-Healing Supramolecular Rubbers by Introducing Ionic Cross-Links into Natural Rubber Via a Controlled Vulcanization. ACS Appl. Mater. Interfaces 2016, 8 (27), 17728-17737.

17. Xu, C.; Cao, L.; Huang, X.; Chen, Y.; Lin, B.; Fu, L., Self-Healing Natural Rubber with Tailorable Mechanical Properties Based on Ionic Supramolecular Hybrid Network. ACS Appl. Mater. Interfaces 2017, 9 (34), 29363-29373.

18. Masayuki, Y.; Rika, M.; Ryota, K.; Tadashi, W.; Susumu, O.; Shogo, N., Autonomic Healing and Welding by Interdiffusion of Dangling Chains in a Weak Gel. Polym. Int. 2012, 61 (1), 9-16.

19. Hernández Santana, M.; den Brabander, M.; García, S.; van der Zwaag, S., Routes to Make Natural Rubber Heal: A Review. Polym. Rev. 2018, 10.1080/15583724.2018.1454947, 125.

20. Wu, D. Y.; Meure, S.; Solomon, D., Self-Healing Polymeric Materials: A Review of Recent Developments. Prog. Polym. Sci. 2008, 33 (5), 479-522.

21. Li, J. H.; Zhang, G. P.; Deng, L. B.; Zhao, S. F.; Gao, Y. J.; Jiang, K.; Sun, R.; Wong, C. P., In Situ Polymerization of Mechanically Reinforced, Thermally Healable Graphene Oxide/Polyurethane Composites Based on Diels-Alder Chemistry. J. Mater. Chem. A 2014, 2 (48), 20642-20649.

22. Xu, Y.; Chen, D., Self-Healing Polyurethane/Attapulgite Nanocomposites Based on Disulfide Bonds and Shape Memory Effect. Mater. Chem. Phys. 2017, 195, 40-48.

23. Kuang, X.; Liu, G. M.; Dong, X.; Wang, D. J., Enhancement of Mechanical and SelfHealing Performance in Multiwall Carbon Nanotube/Rubber Composites Via Diels-Alder Bonding. Macromol. Mat. Eng. 2016, 301 (5), 535-541.

24. Hernández, M.; Bernal, M. M.; Grande, A. M.; Zhong, N.; van der Zwaag, S.; García, S. J., Effect of Graphene Content on the Restoration of Mechanical, Electrical and Thermal Functionalities of a Self-Healing Natural Rubber. Smart Mater. Struct. 2017, 26 (8), 085010.

25. Fu, G. H.; Yuan, L.; Liang, G. Z.; Gu, A. J., Heat-Resistant Polyurethane Films with Great Electrostatic Dissipation Capacity and Very High Thermally Reversible Self-Healing Efficiency Based on Multi-Furan and Liquid Multi-Maleimide Polymers. J. Mater. Chem. A 2016, 4 (11), 4232-4241.

26. Karger-Kocsis, J.; Meszaros, L.; Barany, T., Ground Tyre Rubber (Gtr) in Thermoplastics, Thermosets, and Rubbers. J. Mater. Sci. 2013, 48 (1), 1-38.

27. Ramarad, S.; Khalid, M.; Ratnam, C. T.; Chuah, A. L.; Rashmi, W., Waste Tire Rubber in Polymer Blends: A Review on the Evolution, Properties and Future. Prog. Mater. Sci. 2015, 72 (Supplement C), 100-140.

28. Sienkiewicz, M.; Janik, H.; Borzędowska-Labuda, K.; Kucińska-Lipka, J., Environmentally Friendly Polymer-Rubber Composites Obtained from Waste Tyres: A Review. J. Clean. Prod. 2017, 147, 560-571.

29. Kojima, M.; Tosaka, M.; Ikeda, Y., Chemical Recycling of Sulfur-Cured Natural Rubber Using Supercritical Carbon Dioxide. Green Chem. 2004, 6 (2), 84-89.

30. Wolf, S.; Plenio, H., On the Ethenolysis of End-of-Life Tire Granulates. Green Chem. 2013, $15(2), 315-319$.

31. Flory, P. J.; Rehner, J., Statistical Mechanics of Cross-Linked Polymer Networks Ii Swelling. J. Chem. Phys. 1943, 11 (11), 521-526.

32. Bode, S.; Enke, M.; Hernández, M.; Bose, R. K.; Grande, A. M.; van der Zwaag, S.; Schubert, U. S.; García, S. J.; Hager, M. D., Characterization of Self-Healing Polymers: From Macroscopic Healing Tests to the Molecular Mechanism In Adv. Polym. Sci., Springer: 2015.

33. Canadell, J.; Goossens, H.; Klumperman, B., Self-Healing Materials Based on Disulfide Links. Macromolecules 2011, 44 (8), 2536-2541.

34. Pepels, M.; Filot, I.; Klumperman, B.; Goossens, H., Self-Healing Systems Based on Disulfide-Thiol Exchange Reactions. Polymer Chem. 2013, 4 (18), 4955-4965. 
35. Abdolah Zadeh, M.; Esteves, C.; van der Zwaag, S.; Garcia, S. J., Healable Dual Organic-Inorganic Crosslinked Sol-Gel Based Polymers: Crosslinking Density and Tetrasulfide Content Effect. J. Polym, Sci. Pol. Chem. 2014, 52 (14), 1953-1961.

36. Brydson, J. A., Rubbery Materials and Their Compounds. Elsevier Science Publishers Ltd: London, 1988, p 469.

37. Hofmann, W., Vulcanization and Vulcanizing Agents. Marclaren and Sons Limited: 1967.

38. Berki, P.; Karger-Kocsis, J., Comparative Properties of Styrene-Butadiene Rubbers (Sbr) Containing Pyrolytic Carbon Black, Conventional Carbon Black, and Organoclay. $J$. Macromol. Sci. B 2016, 55 (7), 749-763.

39. Mathew, G.; Huh, M. Y.; Rhee, J. M.; Lee, M. H.; Nah, C., Improvement of Properties of Silica-Filled Styrene-Butadiene Rubber Composites through Plasma Surface Modification of Silica. Polym. Advan. Technol. 2004, 15 (7), 400-408.

40. Sae-oui, P.; Sirisinha, C.; Thepsuwan, U.; Hatthapanit, K., Comparison of Reinforcing Efficiency between Si-69 and Si-264 in a Conventional Vulcanization System. Polym. Test. 2004, 23 (8), 871-879.

41. Sae-oui, P.; Sirisinha, C.; Thepsuwan, U.; Hatthapanit, K., Roles of Silane Coupling Agents on Properties of Silica-Filled Polychloroprene. Eur. Polym. J. 2006, 42 (3), 479-486.

42. Nelson, P. A.; Kutty, S. K. N., Effect of Silane Coupling Agent on Cure Characteristics and Mechanical Properties of Chloroprene Rubber/Reclaimed Rubber Blend. Polym.-Plast. Technol. Eng. 2004, 43 (4), 1141-1156.

43. Imbernon, L.; Oikonomou, E. K.; Norvez, S.; Leibler, L., Chemically Crosslinked yet Reprocessable Epoxidized Natural Rubber Via Thermo-Activated Disulfide Rearrangements. Polymer Chem. 2015, 6 (23), 4271-4278.

44. Hager, M. D.; van der Zwaag, S.; Schubert, U. S., Self-Healing Materials. Springer International Publishing: 2016.

45. Roberto, M.; Alaitz, R.; Alaitz Ruiz de, L.; Pablo, C.; Damien, D.; Germán, C.; Hans, J. G.; Ibon, O., Dynamic Sulfur Chemistry as a Key Tool in the Design of Self-Healing Polymers. Smart Mater. Struct. 2016, 25 (8), 084017.

46. Tobolsky, A. V.; MacKnight, W. J.; Takahashi, M., Relaxation of Disulfide and Tetrasulfide Polymers. J. Phys. Chem. 1964, 68 (4), 787-790.

47. Xiang, H. P.; Rong, M. Z.; Zhang, M. Q., A Facile Method for Imparting Sunlight Driven Catalyst-Free Self-Healability and Recyclability to Commercial Silicone Elastomer. Polymer 2017, 108, 339-347.

48. Naebpetch, W.; Junhasavasdikul, B.; Saetung, A.; Tulyapitak, T.; Nithi-Uthai, N., Influence of Filler Type and Loading on Cure Characteristics and Vulcanisate Properties of Sbr Compounds with a Novel Mixed Vulcanisation System. Plast. Rubber Compos. 2017, 46 (3), 137-145.

49. Hassan, H. H.; Ateia, E.; Darwish, N. A.; Halim, S. F.; Abd El-Aziz, A. K., Effect of Filler Concentration on the Physico-Mechanical Properties of Super Abrasion Furnace Black and Silica Loaded Styrene Butadiene Rubber. Mater. Design 2012, 34, 533-540.

50. Chen, L.; Jia, Z.; Tang, Y.; Wu, L.; Luo, Y.; Jia, D., Novel Functional Silica Nanoparticles for Rubber Vulcanization and Reinforcement. Compos. Sci. Technol. 2017, 144, 11-17.

51. Fernández-Berridi, M. J.; González, N.; Mugica, A.; Bernicot, C., Pyrolysis-Ftir and Tga Techniques as Tools in the Characterization of Blends of Natural Rubber and Sbr. Thermochim. Acta 2006, 444 (1), 65-70.

52. Motiee, F.; Taghvaei-Ganjali, S.; Malekzadeh, M., Investigation of Correlation between Rheological Properties of Rubber Compounds Based on Natural Rubber/Styrene-Butadiene Rubber with Their Thermal Behaviors. Int. J. Ind. Chem. 2013, 4 (1), 1-16.

53. Lamminmäki, J.; Li, S.; Hanhi, K., Feasible Incorporation of Devulcanized Rubber Waste in Virgin Natural Rubber. J. Mater. Sci. 2006, 41 (24), 8301-8307.

54. Sreeja, T. D.; Kutty, S. K. N., Styrene Butadiene Rubber/Reclaimed Rubber Blends. Int. J. Polym. Mater. Po. 2003, 52 (7), 599-609. 
55. Gibala, D.; Hamed, G. R., Cure and Mechanical Behavior of Rubber Compounds Containing Ground Vulcanizates. Part I—Cure Behavior. Rubber Chem. Technol. 1994, 67 (4), 636-648.

56. Gibala, D.; Hamed, G. R.; Zhao, J., Tensile Behavior of an Sbr Vulcanizate Containing a Single Rubber Particle. Rubber Chem. Technol. 1998, 71 (5), 861-865.

57. Li, S.; Lamminmäki, J.; Hanhi, K., Effect of Ground Rubber Powder on Properties of Natural Rubber. Macromol. Symp. 2004, 216 (1), 209-216.

58. Hosseini, S. M.; Torbati-Fard, N.; Kiyani, H.; Razzaghi-Kashani, M., Comparative Role of Interface in Reinforcing Mechanisms of Nano Silica Modified by Silanes and Liquid Rubber in Sbr Composites. J. Polym. Res. 2016, 23 (9), 203.

59. Ghorai, S.; Bhunia, S.; Roy, M.; De, D., Mechanochemical Devulcanization of Natural Rubber Vulcanizate by Dual Function Disulfide Chemicals. Polym. Degrad. Stabil. 2016, 129, $34-46$. 


\section{SUPPLEMENTARY INFORMATION}

Design of a new generation of sustainable SBR compounds with good trade-off between mechanical properties and self-healing ability

Marianella Hernández Santana*, María Huete, Patricia Lameda, Javier Araujo, Raquel Verdejo and Miguel A. López-Manchado

Institute of Polymer Science and Technology (ICTP-CSIC), Juan de la Cierva 3, Madrid 28006, Spain

*corresponding author: marherna@ictp.csic.es

\section{S1. Tensile curves of SBR compounds}
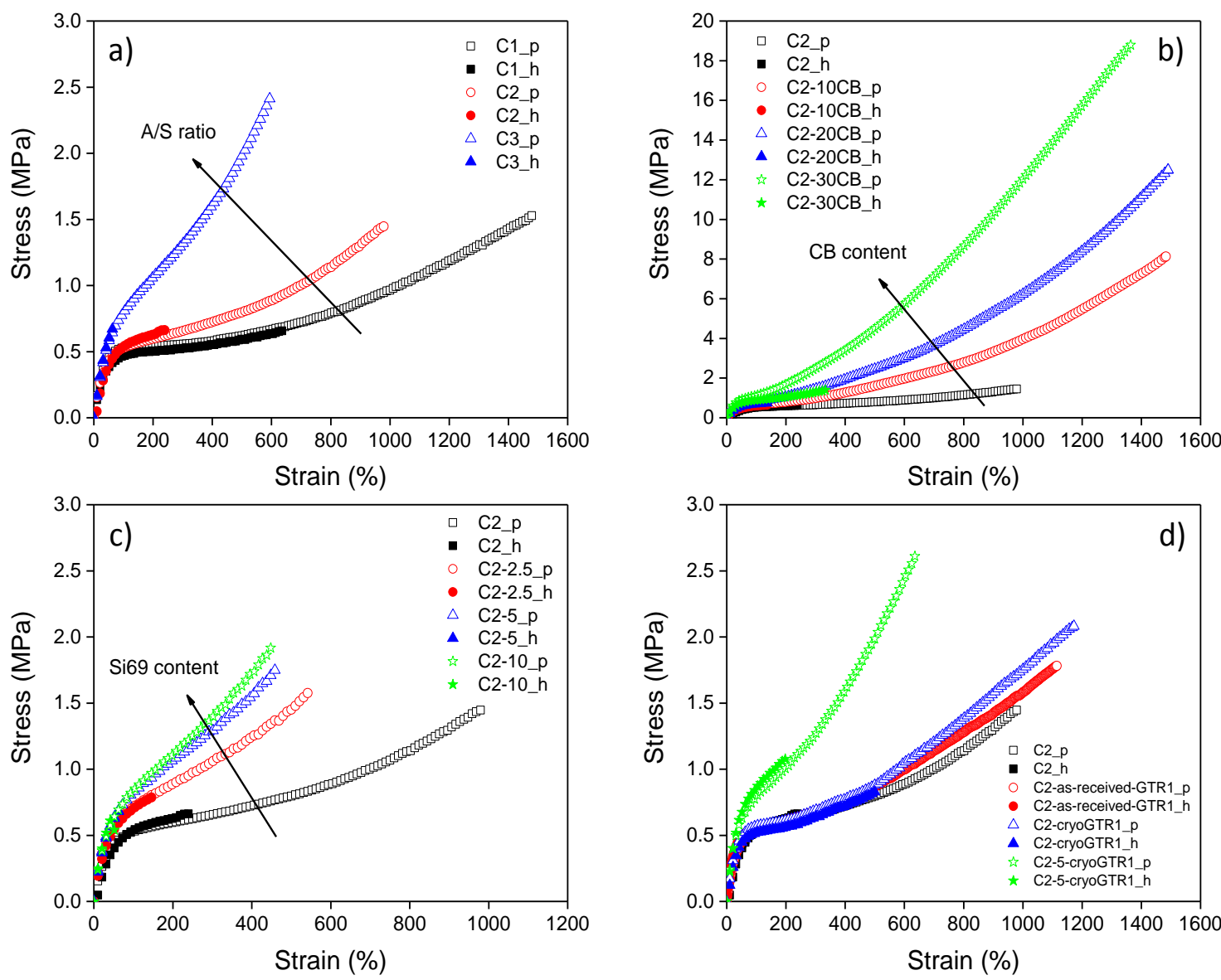

Figure 1S. Stress-strain curves of pristine and healed SBR compounds: a) effect of A/S ratio; b) effect of CB content; c) effect of TESPT content; d) effect of GTR type. In all curves "p" stands for pristine and " $h$ " for healed compounds. 
S2. Schematic reaction of TESPT with SBR

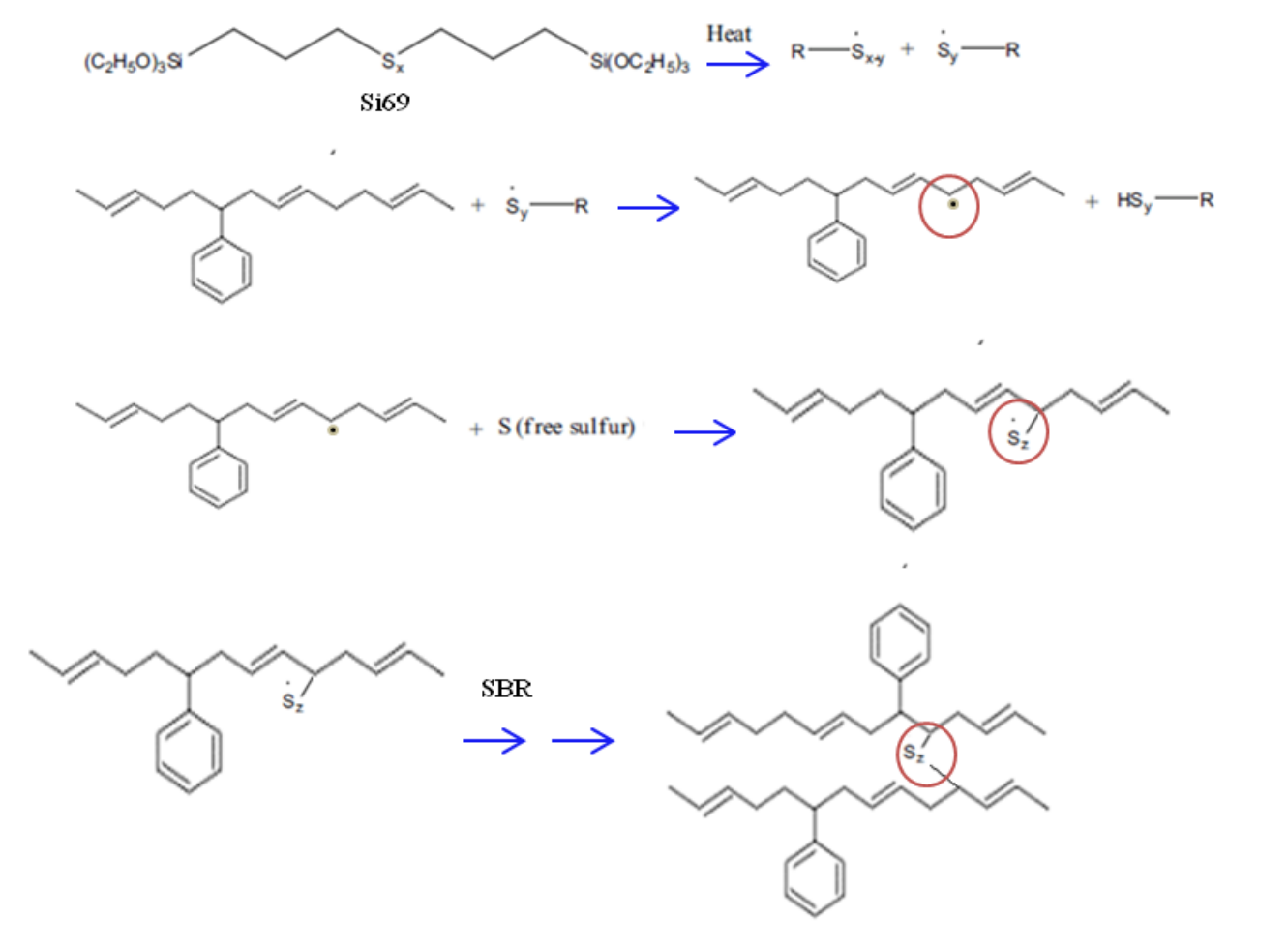

S3. Tg values obtained by DSC

\begin{tabular}{|l|c|}
\hline Compound & $\mathbf{T g}\left({ }^{\circ} \mathbf{C}\right)$ \\
\hline $\mathrm{C} 1$ & -50 \\
\hline $\mathrm{C} 2$ & -49 \\
\hline $\mathrm{C} 3$ & -45 \\
\hline $\mathrm{C} 2-10 \mathrm{CB}$ & -47 \\
\hline $\mathrm{C} 2-20 \mathrm{CB}$ & -47 \\
\hline $\mathrm{C} 2-30 \mathrm{CB}$ & -47 \\
\hline
\end{tabular}


S4. Characteristic Raman and NMR spectrum of sulfur-cured SBR compounds
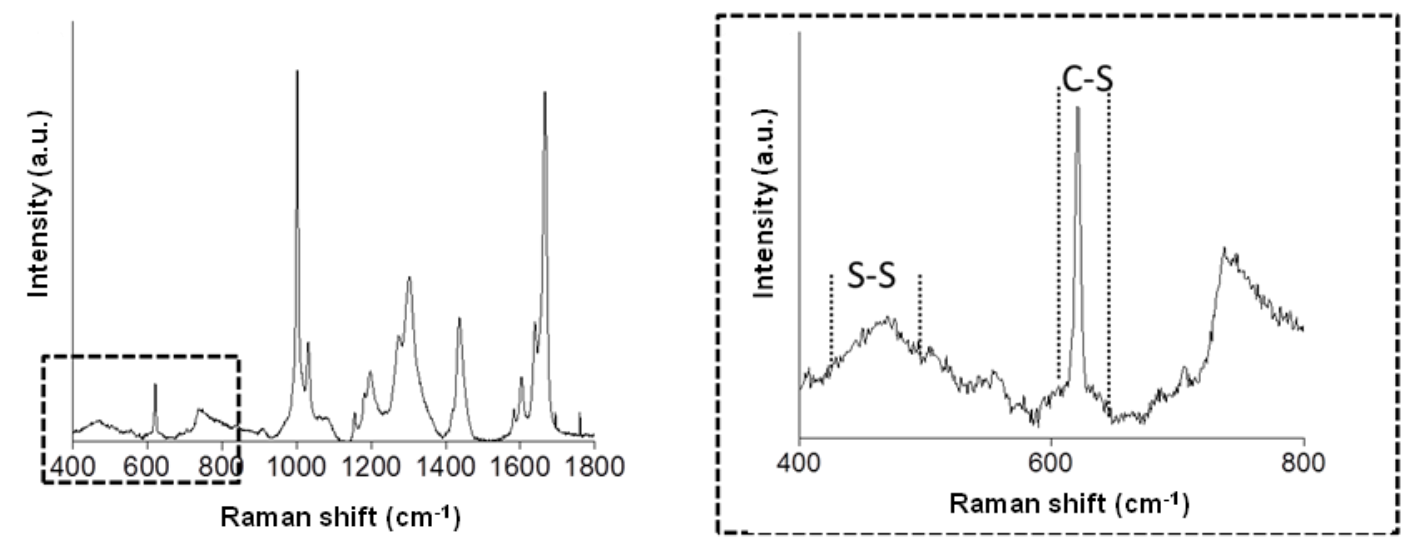

Figure 2S. Raman spectrum of sulfur-cured SBR.
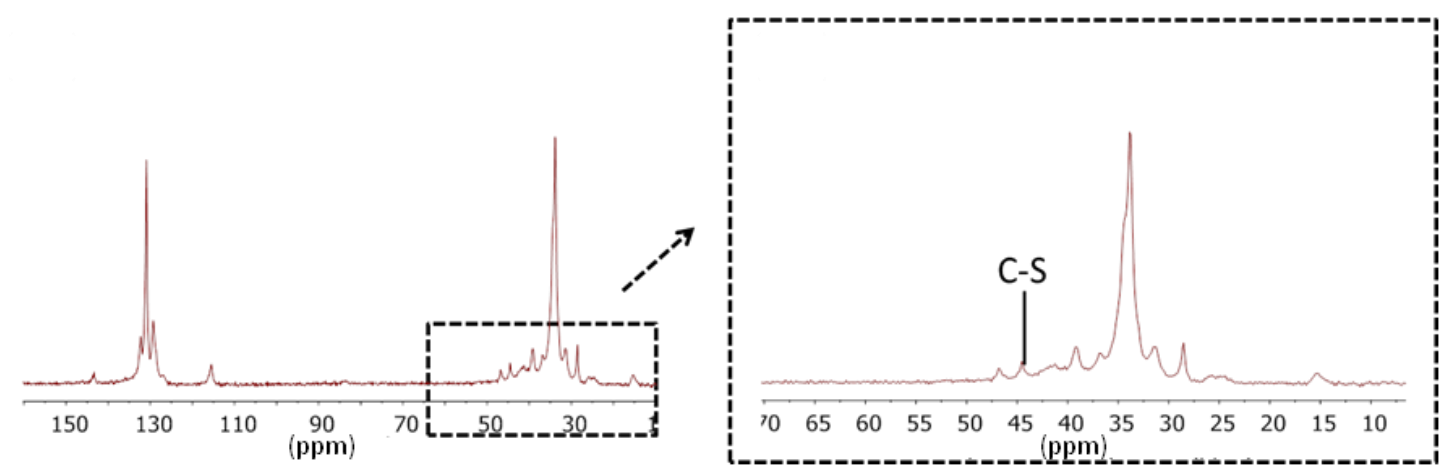

Figure 3S. ${ }^{13} \mathrm{C}$ NMR spectrum of sulfur-cured SBR. 